\title{
ERA DAS BATUCADAS: \\ O CARNAVAL BAIANO DAS DÉCADAS 1930 E 1940*
}

Scott Ickes ${ }^{* *}$

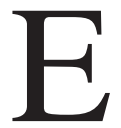

m 1942, o poeta soteropolitano, jornalista e editor de revistas ilustradas, Áureo Contreiras escreveu uma crônica para o jornal A Tarde intitulada "O valor dos cordões e das batucadas no carnaval". Em sua crônica, reeditada no ano seguinte no Diário de Notícias, ele argumentava que as instituições carnavalescas populares dos bairros mais pobres, incluindo as batucadas percussivas afro-baianas, eram "os fatores reais dos folguedos", e a parte mais autêntica "da alma carnavalesca". ${ }^{1}$ Com este argumento Contreiras apelava para o discurso nacionalista, em voga na década de 1940, de que o Brasil era uma mistura de índio, africano e português, "as três raças tristes", cujos "gritos e cânticos" enchiam as ruas durante o carnaval. Os cordões e batucadas eram fruto das alegrias e das dificuldades e amarguras do cotidiano popular. O "verdadeiro" carnaval, dizia Contreiras, era o praticado pelas classes trabalhadoras afro-baianas e por trabalhadores pobres de Salvador. Destacava também o pandeiro, a cuíca e o reco-reco e "todos os instrumentos bárbaros evocativos do passado nas senzalas e nos "terreiros", como vínculos com um passado baiano que era, ao

\footnotetext{
Tradução de Mariângela de Mattos Nogueira

** Professor Assistente do Departamento de História da Universidade do Sul da Florida. O autor deseja agradecer a Joêlia Brito, Alane Fraga do Carmo, e Cínthia da Cunha pela assistência na pesquisa; aos entrevistados por partilharem seu tempo, experiências e conhecimentos; a Vera Nathália dos Santos Silva pela assistência nas entrevistas e transcrições; e a Jolie Dyl, Kees Boterbloem, Greg Milton e Willys Santos de Andrade pelos comentários e sugestões úteis em versões anteriores. sickes@usf.edu

1 A Tarde, 9 de fevereiro de 1942; Diário de Notícias, 8 de março de 1943.
} 
mesmo tempo, central para a formação cultural do Brasil, assim como para o presente cultural da Bahia.

$\mathrm{O}$ argumento de Contreiras revela um protagonismo afro-baiano a empurrar a "cultura negra" - as batucadas em particular - para a vanguarda do carnaval baiano. ${ }^{2}$ Emergente na década de 1930, as batucadas institucionalizaram e ritualizaram as práticas musicais e sociabilidades da classe trabalhadora afro-baiana no carnaval da Bahia. Afrobaianos souberam aproveitar o poder transformador desta festa para pressionar e obter maior relevância cultural e simbólica no carnaval da cidade, e além dele. A natureza lúdica do carnaval permite a indivíduos ou grupos transcender, expandir ou engrandecer a si mesmos e à sua condição social em espaços públicos. ${ }^{3}$ Isto não quer dizer que o carnaval represente um momento igualitário, livre do seu contexto históricoestrutural. Ao contrário, o carnaval é um espaço disputado em que a performance e o ritual contribuem para as negociações sobre o significado social dos modos que podem ou não influenciar a organização social durante o resto do ano. ${ }^{4}$

2 As batucadas eram parte de um universo cultural mais amplo que remonta ao período colonial. Para trabalhos recentes sobre batuque, candomblé e festividades populares no período colonial e primeira metade do século XIX ver, entre outros, Silvia Hunold Lara, "Significados cruzados: um reinado de congos na Bahia setecentista", in Maria Clementina Pereira Cunha (org.), Carnavais e outras f(r)estas: ensaios de história social da cultura (Campinas: Editora da Unicamp / CECULT / FAPESP, 2002), pp. 71-100; João José Reis, "Tambores e temores: a festa negra na Bahia na primeira metade do século XIX", in Maria Clementina Pereira Cunha (org.), Carnavais e outras f(r)estas, pp. 101-47; João José Reis, Death Is a Festival: Funeral Rites and Rebellion in Nineteenth-Century Brazil, Chapel Hill: University of North Carolina Press, 2003.

3 Victor Turner, The Anthropology of Performance, Nova York: PAJ Publications, 1986; Richard Burton, Afro-Creole: Power, Opposition, and Play in the Caribbean, Ithaca, NY: Cornell University Press, 1997, capítulo 4; Natalie Zemon Davis, Society and Culture in Early Modern France: Eight Essays, Stanford: Stanford University Press, 1975, capítulos 4 e 5; Roberto da Matta, Carnivals, Rogues, and Heroes: An Interpretation of the Brazilian Dilemma, Notre Dame: University of Notre Dame Press, 1991. Também sobre o poder do lúdico, ver Richard Schechner, "Carnival (Theory) After Bakhtin", in Milla Cozart Riggio (org.), Carnival: Culture in Action - The Trinidad Experience (London: Routledge, 2004), pp. 9-10. Enfatizando o poder do carnaval em Salvador além do seu tempo e lugar oficiais, Piers Armstrong, "Bahian Carnival and Social Carnivalesque in Trans-Atlantic Context", Social Identities v. 16, n. 4 (2010), p. 449, nota, para o início do século 21, que "as fronteiras temporais e espaciais entre o carnaval e a cultura do quotidiano são relativamente abertas, de modo que os dois domínios são menos polarizados e seus respectivos modos performativos convergem".

4 O carnaval oferece não apenas caminhos de resistência racial e de classe contra a cultura dominante, mas também mecanismos pelos quais a classe dominante coopta e circunscreve as iniciativas subalternas, ou reforça o status quo. Matta, Carnavals, emprega o trabalho de Victor Turner para atualizar a interpretação de Bahktin do carnaval como um momento de democracia catártica e resistência simbólica às estruturas repressivas e exploradoras que ordenaram a vida diária. Maria Isaura Pereira de Queiroz, Carnaval brasileiro: o vivido e o mito, São Paulo: Editora Brasiliense, 


\section{O artigo de Contreiras refletia e contribuía para uma reavaliação,}

pela classe dominante, do lugar da cultura afro-baiana no carnaval, o que era parte de uma reavaliação mais ampla e relativamente de maior alcance da cultura afro-baiana e suas contribuições para a baianidade depois de $1930 .{ }^{5}$ No contexto do carnaval, esta reavaliação foi amplamente realizada nos artigos e editoriais escritos por membros da influente "Associação de Cronistas do Carnaval", da qual Contreiras fazia parte. Os cronistas eram os principais comentaristas dos acontecimentos dos três dias de festa e desempenhavam um papel central na reelaboração da organização e dos significados do carnaval baiano desde o

1992, discorda, argumentando que Da Matta ignorou a hierarquia e o poder diferenciados que ainda estavam presentes durante o carnaval e que o sistema de valores da burguesia dominante domesticou o carnaval por muitos anos. A maioria dos estudiosos do carnaval no Brasil marca suas posições entre esses dois pólos. Ver Renato Ortiz, A consciência fragmentada: ensaios de cultura popular e religião, Rio de Janeiro: Paz e Terra, 1980, em particular pp. 13-27; Robert Stam, "Carnival, Politics and Brazilian Culture", Studies in Latin American Popular Culture, n. 7 (1988), pp. 255-64; Rachel Soihet, A subversão pelo riso: estudos sobre o carnaval carioca da Belle Époque ao tempo de Vargas, Rio de Janeiro: Fundação Getulio Vargas, 1998; Maria Laura Viveiros de Castro Cavalcanti, $O$ rito e o tempo: ensaios sobre o carnaval, Rio de Janeiro: Civilização Brasileira, 1999. Ver também, Alison Raphael, "Samba and Social Control: Popular Culture and Racial Democracy in Rio De Janeiro" (Tese de Doutorado, Columbia University, 1980); Dulce Tupy, Carnavais de guerra: o nacionalismo no samba, Rio de Janeiro: ASB Arte Gráfica e Editora, 1985; Jairo Severiano, Getúlio Vargas e a música popular, Rio de Janeiro: Fundação Getúlio Vargas, 1983; Cláudia Matos, Acertei no milhar: malandragem e samba no tempo de Getúlio, Rio de Janeiro: Paz e Terra, 1982; Maria Clementina Pereira Cunha, Ecos da folia: uma história social do carnaval carioca entre 1880 e 1920, São Paulo: Companhia das Letras, 2001.

5 Sobre aspectos dessa ampla reavaliação, ver Vivaldo da Costa Lima, "O candomblé da Bahia na década de trinta" in Vivaldo da Costa Lima e Waldir Freitas Oliveira (orgs.), Cartas de Édison Carneiro a Artur Ramos (São Paulo: Corrupio, 1987), pp. 37-73; Waldir Freitas Oliveira, "Os estudos africanistas na Bahia dos anos 30" in Vivaldo da Costa Lima e Waldir Freitas Oliveira (orgs.), Cartas de Édison Carneiro a Artur Ramos, pp. 23-35; Beatriz Góis Dantas, Vovó nagô e papai branco: usos e abusos da África no Brasil, Rio de Janeiro: Graal, 1988, pp. 161-201; Angela Lühning, “'Acabe com este santo, Pedrito vem aí...' mito e realidade da perseguição policial ao candomblé baiano entre 1920 e 1942, Revista da USP, n. 28 (1995/1996), pp. 194-220; Júlio Santana Braga, Na gamela do feitiço: repressão e resistência nos Candomblés da Bahia, Salvador: Edufba, 1996; Kim Butler, Freedoms Given, Freedoms Won: Afro-Brazilians in Post-Abolition, São Paulo and Salvador, New Brunswick, N.J.: RutgersUniversity Press, 1998, capítulo 6; Kim Butler, "Afterword: Ginga Baiana, The politics of Race, Class, Culture, and Power in Salvador, Bahia", in Hendrick Kraay (org.), Afro-Brazilian Culture and Politics: Bahia, 1790s to 1990s (Londres: ME Sharpe, 1998), pp. 158-75; Scott Ickes, "Salvador's Transformist Hegemony: Popular Festivals, Cultural Politics and Afro-Bahian Culture in Salvador, Bahia, Brazil, 1930-1952", (Tese de Doutorado, Universidade de Maryland, 2003); Lisa Earl Castillo, Entre a oralidade e a escrita: a etnografia nos candomblés da Bahia, Salvador: Edufba, 2008, pp. 101-44; Roger Sansi-Roca, Fetishes and Monuments: Afro-Brazilian Art and Culture in the Twentieth Century, Nova York: Berghahn Books, 2007, pp. 51-141; Anadelia Romo, Brazil's Living Museum: Race, Reform and Tradition in Bahia, Chapel Hill: University of North Carolina Press, 2010. 
seu início até meados do século XX, do modo como as pessoas e grupos participavam (ou não participavam), e como os soteropolitanos pensavam as festividades em relação a eles mesmos e ao Brasil. A narrativa historiográfica do carnaval baiano, no entanto, quase não reconhece o período entre 1930 e 1950. A história convencional normalmente começa com o surgimento do "carnaval oficial" da década de 1880, majoritariamente branco, com seus desfiles grandiosos, ao lado de um "carnaval popular" composto por uma grande variedade de associações menores, incluindo as organizadas pelos afro-baianos. ${ }^{6}$ A partir desse ponto, a narrativa salta para 1949, ano de fundação do afoxé Filhos de Gandhy, e, logo em seguida, para a criação do trio elétrico em 1951. Certamente, o Filhos de Gandhy, hoje muito maior, é uma das imagens visuais mais impressionantes do carnaval baiano. $\mathrm{O}$ trio elétrico, inicialmente um trio de músicos tocando música amplificada em cima de uma caminhonete Ford, que vem sendo atualizado desde 1951, faz o carnaval contemporâneo, com suas atrações comerciais. No entanto, as mudanças no carnaval baiano entre 1930 e 1950 foram significativas e, avaliar o crescimento das batucadas e sua inclusão pela cultura dominante permite uma melhor compreensão da trajetória histórica da identidade regional e da política cultural baiana entre o final do século XIX e segunda metade do século XX.

O carnaval baiano, desde os seus primórdios na década de 1880 , tinha se centrado no desfile oficial organizado pela elite da cidade, cujo eixo central eram os carros alegóricos dos três grandes clubes - Cruz Vermelha, Inocentes em Progresso e Fantoches da Euterpe. Depois de 1930, no entanto, os clubes de elite caíram em um prolongado período de dificuldades financeiras, que espelhava o relativo declínio da própria situação econômica de Salvador, um período que durou até a década de 1950. Consequentemente, o "carnaval popular" e os pequenos clubes preencheram o vácuo, forçando um reequilíbrio na formulação dos significados do carnaval da Bahia. Do final da década de 1930 aos

6 Butler, Freedoms Given, Freedoms Won, pp. 172-75; Peter Fry, Sérgio Carrara e Ana Luiza Martins-Costa, "Negros e brancos no carnaval da Velha República", in João José Reis (org.), Escravidão e invenção da liberdade: estudos sobre o negro no Brasil (São Paulo: Editora Brasiliense, 1988); Alberto Heráclito Ferreira Filho, "Desafricanizar as ruas: elites letradas, mulheres pobres e cultura popular em Salvador (1890-1937)", Afro-Ásia, n. 21-2 (1999 1998), pp. 239-56. 
últimos anos da de 1950, as associações carnavalescas afro-baianas, em especial as batucadas e seu preferido gênero musical, o samba, aumentaram sua presença pública durante os três dias de celebrações, tornando-se características marcantes desse mais famoso carnaval de rua. As batucadas tocavam sambas criados pela indústria musical, mas também escreviam e tocavam suas próprias letras e músicas e, portanto, representavam uma manifestação pública de uma espécie crua, nãocomercializada de afro-baianidade. A intensa década de 1940 foi realmente a "Era das Batucadas".

Depois de 1950, os clubes de elite recuperaram sua situação financeira, mas não recuperariam seu domínio quase total sobre a forma, o conteúdo ou o significado do carnaval. Por mais de uma década a balança do carnaval de Salvador favoreceu as práticas festivas populares da classe trabalhadora afro-baiana como o indicador simbólico central da identidade do carnaval de Salvador. A importância do samba e das batucadas para o carnaval tinha estabelecido, no discurso dominante, uma relação permanente e poderosa entre a afro-baianidade e o carnaval baiano. Essas mudanças foram reforçadas por outros fatores específicos do período, tais como a reanimação dos afoxés no final da década de 1940, do que é exemplo o Filhos de Gandhy. ${ }^{8}$ Além disso, o carnaval em Salvador ficou mais popular na medida em que o número de clubes menores, incluindo as batucadas, aumentou e se espalhou nos bairros populares da cidade. Por outro lado, a partir da década de 1930, soteropolitanos comuns espalharam as festividades do carnaval popular além de sua tradicional demarcação, invadindo o espaço ritual das outras grandes festas populares, ampliando a inclusão da cultura afrobaiana, como o samba e as batucadas, dentro da prática ritual festiva além dos limites espaciais e temporais do calendário do carnaval. ${ }^{9}$ Sobretudo, a partir de um ponto de vista performativo, o desaparecimento dos clubes de elite e o aumento dos pequenos clubes, entre as décadas de 1930 e 1940, deslocaram a ênfase do discurso oficial do carnaval dos

7 O historiador baiano Cid Teixeira, "Prefácio", in Anísio Félix (org.), Filhos de Gandhi: a história de um afoxé (Bahia: Gráfica Central, 1987) foi o primeiro a se referir aos anos 1940 como a "Era das Batucadas".

8 Um afoxé, algumas vezes referido como "candomblé da rua", era uma extensão da cultura e das pessoas de um terreiro específico organizado para celebrar o carnaval.

9 Ver Scott Ickes, African-Brazilian Culture and Regional Identity in Bahia, Brazil (University of Florida Press, no prelo), capítulo 5. 
três clubes para um evento dominado, em parte - e dentro de limites que deverão ser explorados a seguir - pela participação ativa dos populares, e associado às contribuições dos afro-baianos e da cultura afrobaiana.

\section{O carnaval de Salvador durante a República Velha}

O predecessor do carnaval foi o entrudo, importado de Portugal e caracterizado por batalhas de rua e jogos faceiros entre mulheres e homens, que envolviam bombas de água e farinha. Esta era, em grande parte, uma atividade da classe alta, enquanto os escravos e serviçais trabalhavam para equipar seus senhores com água e suprimentos, preparar as refeições festivas e lavar a roupa extra. Escravos e serviçais também podiam ser vítimas da cultura brincalhona e travessa do entrudo, mas podiam, junto com os negros livres, também encontrar tempo para festejar entre si. Teoricamente, o entrudo foi proibido ainda em 1853, em grande parte por ser incompatível com a "civilização". Na prática, as brincadeiras e comportamentos desordeiros continuaram até a década de 1880, mesmo depois de a polícia baiana as ter "proibido definitivamente" em 1878. No entanto, a imprensa baiana continuou a denunciar e se desesperar com tal comportamento até 1901, atacando-o como "bárbaro" e "incivilizado", associando-o à cultura festiva afro-baiana. ${ }^{10}$

O surgimento de cortejos organizados, na década de 1880, marcou o início do moderno carnaval de rua de Salvador, visto pela elite como evento mais ordenado e familiar para substituir o popular e promíscuo entrudo. Em 1884, uma instituição do carnaval de elite, o clube Cruz Vermelha, tomou a iniciativa de desfilar pelas principais ruas da cidade. Isto inspirou outros jovens de famílias da elite a, no ano seguinte, levar um segundo clube carnavalesco, Fantoches da Euterpe, para as ruas. Logo haveria três grandes clubes competindo, depois que "dissidentes" do Cruz Vermelha fundaram o Inocentes em Progresso. Todos os três grandes clubes foram dominados pelos e atendiam aos interesses da elite e da pequena classe média de Salvador. Seu formato e prestígio dominaram o carnaval oficial de Salvador durante toda a Primeira Re-

10 Butler, Freedoms Given, Freedoms Won, pp. 172-75; Hildegardes Vianna, "Do entrudo ao carnaval na Bahia", Revista Brasileira de Folclore, n. 13 (1965), p. 285. Ver também Fry et alli., "Negros e brancos"; Ferreira Filho, "Desafricanizar as ruas". 
pública (1889-1930), eles dispunham de recursos e construíam enormes e complexos carros alegóricos, que tratavam de temas escolhidos e desfilavam pelo centro da cidade no domingo, antes da terça-feira gorda. As multidões ao longo do percurso jogavam pétalas de rosas, confetes e serpentinas, aplaudindo seus favoritos. Os políticos se associavam aos clubes de elite e o governo municipal os subsidiava. Estes clubes importavam a maioria dos materiais para os seus carros alegóricos e fantasias da França, Itália ou Inglaterra. Não surpreendentemente, as suas apresentações e atividades recorreram à moda carnavalesca europeia para sua inspiração, particularmente a do carnaval de Veneza, e este período é muitas vezes referido como a era do carnaval veneziano. Os clubes de elite realizavam batalhas de confete e bailes de máscaras para os seus membros nas noites de sexta-feira e sábado nos teatros de São João e Politeama. A extensa cobertura jornalística do carnaval, antes de 1930, focava predominantemente os preparativos e performances destes clubes. Mesmo durante os anos em que não saíram (por razões financeiras ou outras internas), eles foram, para a maioria dos jornalistas, "europeus" e, portanto, o ideal de civilização e modernidade pelo qual todas as associações carnavalescas menores eram (pré-) julgadas.

Muitos outros clubes menores também participavam do carnaval durante este período. Inicialmente, a maioria deles era de classe média, com nomes como Cavalheiros de Malta ou Filhos de Veneza. Mas devemos hesitar antes de aceitar a afirmação de Olga Von Simson de ser o século XX a era do "carnaval burguês", ao invés de "carnaval popular". ${ }^{11}$ Em Salvador, já em finais de 1890, instituições populares de carnaval eram várias. ${ }^{12}$ Muitas delas eram manifestações carnavalescas das seculares e ricas tradições de batuques afro-baianos, ou encontros festivos, religiosos, ou simplesmente sociáveis em torno de percussão, música e dança. Outros eram simplesmente blocos, enquanto, pelo menos alguns, foram a primeira onda de afoxés. ${ }^{13}$

11 Olga Rodrigues de Moraes Von Simson, "Espaço urbano e folguedo carnavalesco no Brasil: uma visão ao longo do tempo", Cadernos do Centro de Estudos Rurais e Urbanos, n.15, $1^{\mathrm{a}}$ serie (1981). Para Von Simson, o "carnaval popular" surgiu no Rio de Janeiro e São Paulo somente nos anos 1920.

12 Kim Butler encontrou "dezenas" de "afro" clubes depois de 1896, com nomes como Cavaleiros Africanos, Andarilhos Africanos, Caçadores Africanos, Netos da África, Defensores da África, A Embaixada Africana e Foliões Africanos.

13 Butler, Freedoms Given, Freedoms Won, p. 177; Ver também, Fry, et allii, "Negros e brancos", pp. 254-60. 
O relato de tantas pequenas associações "africanizadas" levou Vieira Filho a concluir que, embora o carnaval oficial de Salvador possa ter sido dominado pela burguesia, especialmente após 1904, o carnaval fora do circuito oficial foi muito significativamente da classe trabalhadora ao longo de todo o período, e esmagadoramente assim nos bairros da classe trabalhadora afro-baiana e no entorno do centro da cidade. ${ }^{14}$ De fato, tanto assim que uma vez que o entrudo desapareceu, a elite voltou suas preocupações e críticas às atividades culturais "africanizadas" no espaço público. ${ }^{15}$ Consequentemente, as autoridades locais, a premente pedido dos brancos obcecados com a imitação dos índices europeus de civilização, e reagindo ao medo da classe dominante de perder o controle da capacidade do carnaval para produzir discursos mais amplos de identidade e significado, proibiram todos os clubes afrocêntricos de 1905 a 1914. ${ }^{16}$ Claramente, as décadas anteriores a 1930 foram um período durante o qual a elite baiana, especialmente na década de 1910, ainda se sentia muito vulnerável à possibilidade de, no pós-Abolição, Salvador estar se tornando mais "africana" e menos "europeia", do modo como eles entendiam estes termos, e que isso também significava uma diminuição do poder de controle da elite regional e nacionalmente. ${ }^{17}$

Após a proibição ter sido suspensa, depois da temporada do carnaval de 1914, clubes de carnaval marcadamente afrocêntricos voltaram e cresceram em número até 1920. Na verdade, mesmo antes de 1914, jornais diários da cidade começaram a chamar a atenção para a grande prática de tocar e dançar o samba afro-brasileiro no carnaval baiano. Então, seguindo o lançamento de "Pelo telefone" em 1917, jornalistas escrevendo sobre o carnaval de Salvador de 1918 relataram que o evento foi dedicado ao compromisso explícito com o samba - suas composições e danças. ${ }^{18}$ Mais tarde, na década de 1920, jornalistas escre-

${ }^{14}$ Rafael Rodrigues Vieira Filho, "A africanização do carnaval de Salvador, Bahia: a recriação do espaço carnavalesco (1876-1930)" (Tese de Doutorado, Universidade de São Paulo, 1995), pp. $128-49$.

15 Antonio Risério, "Carnaval, as cores da mudança," Afro-Ásia, n. 16 (1995), p. 92.

16 Journal A Bahia, 16 de fevereiro de 1906; Fry et allii, "Negros e brancos," pp. 255-6.

17 Butler, Freedoms Given, Freedoms Won, pp. 171, 187-8.

18 Donga e Mauro de Almeida, "Pelo telefone", gravação original da Banda Odeon, Odeon, 1917. Ver, Marc Hertzman, "Surveillance and Difference: The Making of Samba, Race, and Nation in Brazil (1880s - 1970s)" (Tese de Doutorado, Universidade de Wisconsin, Madison, 2008), pp. 233-36, para uma discussão do grau em que é legítimo se referir a "Pelo telefone" como samba". 
veram sobre o samba nas ruas e praças (embora não nos cortejos oficiais) de uma maneira que, embora um pouco paternalista e folclórica, ainda era razoavelmente positiva e regionalista. Parece que o samba em Salvador, durante o carnaval em especial, estava na vanguarda da aceitação pela classe dominante das práticas culturais afro-baianas. ${ }^{19}$ No entanto, haveria ainda mais duas décadas antes que o discurso público em Salvador consagrasse o samba no carnaval baiano e estabelecesse retumbantes e positivas associações do maior e mais popular evento cultural da cidade com as batucadas e a herança cultural afro-baiana da região.

O carnaval nas décadas de 1930 e 1940 havia se estabelecido em um modelo ideal. As festividades começavam no domingo e terminavam na noite de terça-feira. O clímax, o desfile principal era normalmente na noite de terça-feira, durante a qual os "dramáticos e luxuriantes" cortejos dos clubes de elite eram a atração principal, sempre povoado com "as visões femininas mais bonitas e distintas da nossa [alta] sociedade". ${ }^{20}$ Os principais personagens sobre estes carros alegóricos eram representados por uma esmagadora maioria de baianos de pele clara, enquanto os papéis menores dentro dos desfiles, mas raramente sobre os próprios carros, eram desempenhados por pessoas tanto de ancestralidade europeia quanto africana. Durante os períodos em que os clubes de elite não desfilaram, ou só tiveram reduzida participação, ainda havia um carnaval oficial dominado pelas instituições da classe dominante, como a Associação Atlética da Bahia e, mais tarde, o Clube Baiano de Tênis. Desfiles menores, alguns com carros alegóricos e automóveis decorados, alguns com músicos a bordo, percorriam de cima a baixo a rota do cortejo, muitas vezes a cada dia, nos domingos e segundas-feiras de carnaval.

A área oficial de maior animação, onde o trânsito era estritamente regulamentado e as multidões bem policiadas, era ao longo da Rua Chile e, mais tarde, também ao longo da Avenida Sete de Setembro. O governo municipal provia iluminação e ornamentação ao longo do percurso oficial do desfile, do Terreiro de Jesus ao Campo Grande. Empre-

19 Butler, Freedoms Given, Freedoms Won, pp. 180-81; Vieira Filho, “Africanização”, pp. 13644. O corta jaca (uma forma de samba) e o maxixe (um precursor do samba) tinham sido incorporados no programa dos cortejos e bailes do carnaval da elite em Salvador no início de 1899, e depois, em 1915, ao lado de aberturas de operas e outras peças de música erudita".

20 O Imparcial, 13 de janeiro 1937. 
sários locais, especialmente aqueles do ramo de hotéis, bares, cafés ou lojas, também contribuíam. Era ao longo desse percurso que as multidões encontravam o seu lugar nos três dias, muitos chegando fantasiados e mascarados, de manhã cedo, muitas vezes em grupos do mesmo sexo, ou individualmente, de diversos bairros da cidade. Ao final do cortejo do dia, os foliões já começavam a se reunir nos bares, clubes mais populares, nas casas de amigos ou parentes, ou voltavam para casa. As máscaras eram proibidas em espaço público depois de seis horas da tarde. Quase todos estavam nas ruas até a meia-noite. ${ }^{21}$

Geograficamente, a emoção também se espalhava para além da Rua Chile, derramando-se na direção da Avenida Sete de Setembro e, na direção oposta, para o Terreiro de Jesus e bairros adjacentes. Fora da rota do desfile principal, os negociantes locais, assumiam a responsabilidade adicional, decorando o espaço público com serpentinas, bandeirolas e iluminação, e até mesmo erguendo palcos para música ao vivo, ou se envolvendo eles mesmos nas brincadeiras de carnaval. Aí, longe do carnaval "oficial", a festa contava com as contribuições de blocos, cordões, batucadas e afoxés menores e locais. A tendência predominante depois de 1930, tanto no centro da cidade como na maioria dos bairros, foi de crescimento de blocos e cordões, e de entrada de mais e mais pessoas nas festividades rituais organizadas. Subsídios públicos para pequenos clubes foram primeiramente mencionados no início da década de 1940, embora jornais patrocinando competições e oferecendo prêmios em dinheiro como incentivo datem de meados da década anterior. ${ }^{22}$ Assim, embora os clubes de elite tivessem sido o foco do carnaval oficial no início do século XX, os clubes pequenos desempenharam o seu papel nas festividades e estavam prontos para emergir de modo mais relevante. Foi a partir de meados da década de 1930 que os blocos, cordões e, especialmente, as batucadas vieram para rivalizar,

${ }^{21}$ José Ferreira, entrevistado pelo autor, Salvador, 4 de novembro de 1999, 44-45, e 11 de novembro de 1999. As entrevistas fazem parte de um levantamento maior de história oral sobre cultura negra e as festas populares em Salvador nos anos 1930, 1940 e 1950. Entrevistei pessoas que viviam em Salvador durante a Era Vargas, que coincide com a das batucadas. Em particular escolhi pessoas da "classe baixa." As três ou quatro entrevistas incluídas no artigo revelavam pequenos detalhes sobre as batucadas e o carnaval. Ver Ickes, African Bahian Culture and Regional Identity. Sobre restrições e censura durante o carnaval ver, Arquivo Público do Estado da Bahia [daqui em diante APEBa], Secretaria de Segurança Pública, Cx 6456 Pc 03, 1906-1943.

22 Diário de Notícias, 10 de março de 1943. 
se não para superar os cortejos de elite como ponto central do carnaval baiano.

\section{Poder e desaparecimento dos clubes de elite}

Nas primeiras décadas do século XX, os clubes de elite prosperavam, enquanto isso a imprensa e os políticos gravitavam em torno do espetáculo e da influência do Cruz Vermelha, Inocentes em Progresso e Fantoches da Euterpe e, assim, melhoravam sua imagem. Embora tenha havido alguma consideração sobre a possibilidade de que Salvador pudesse repetir o sucesso que o Rio de Janeiro estava tendo no seu carnaval com a institucionalização das escolas de samba, em grande parte da classe trabalhadora, a preferência da classe dominante baiana, no entanto, foi claramente a de que os clubes de elite fossem o ponto central das festividades. ${ }^{23}$ A narrativa dominante do período que antecedia o carnaval era o interesse da mídia em saber se os clubes participariam ou não, quem seriam suas rainhas, o que aconteceria em seus eventos e quais seriam os temas de seus carros alegóricos. As tradicionais elites políticas e econômicas baianas, e principalmente seus filhos adultos jovens, continuaram a associar-se inteiramente com os três clubes de elite depois de $1930 .^{24}$

Que o regime político do Estado Novo também tenha se associado aos clubes de elite é algo surpreendente, dada a ênfase de Vargas, no Rio de Janeiro, na cooptação das "escolas de samba" da classe trabalhadora, em uma relação clientelista típica, e da qual os baianos eram bem conscientes. ${ }^{25} \mathrm{Na}$ Bahia, entretanto, representantes do Estado Novo preferiam se conectar com os soteropolitanos nos clubes de elite, tirando vantagem dos laços de lealdade, de longa data, entre as pessoas comuns e esses clubes, e assim, estreitar os vínculos entre as massas e o gover-

23 O Imparcial, 29 de janeiro de 1937.

${ }^{24}$ Durante os anos de 1930 os jornais não mencionavam políticos ou posições políticas relacionadas ao carnaval. Esta era provavelmente uma convenção entre os repórteres naquele momento. Embora, a correspondência esporádica, localizada na Pasta "Clubes Carnavalescos" no Arquivo Histórico Municipal de Salvador, mostre que a prefeitura subsidiava os grandes clubes durante este período.

${ }^{25}$ Os jornais baianos, ocasionalmente, noticiavam eventos do Rio de Janeiro, por exemplo "informava que Getúlio Vargas tenha autorizado o prefeito do Rio a aumentar as contribuições aos clubes carnavalescos do Rio": Diário de Notícias, 11 de fevereiro de 1939. 
no para colher um tanto de benefício político. O governo municipal, antes de 1930, frequentemente dava apoio financeiro para o desfile do carnaval oficial, controlava o tráfego e transporte, estabelecia ligações com as comissões de bairro organizadas por empresários locais, e iluminava e decorava a área central. A partir da década de 1930, a prefeitura começou também a subsidiar a apresentação dos três grandes clubes, que, por sua opulência e proeminência desproporcionadas, características centrais das festividades, certamente simbolizava o poder do membros da elite e legitimava sua posição no topo da sociedade soteropolitana. ${ }^{26}$ Isto, é claro, fazia sentido por uma série de razões, e os próprios clubes não eram tímidos ao salientar isto ao gabinete do prefeito em suas solicitações anuais de subsídios, com as quais eles tinham, por volta de 1940, passado a contar. O benefício, como um ofício afirmava, da prosperidade dos clubes "se reflete no progresso da cidade, intensificando o movimento de seu comércio, sua indústria e suas artes", bem como proporcionava uma merecida "distração musical" para a população da cidade e do estado. ${ }^{27}$ Há também alguma indicação de que quando os três grandes desfilavam, a prefeitura favorecia financeiramente o desfile oficial da Rua Chile, em detrimento das festas mais populares e tradicionais ao longo da Baixa dos Sapateiros. Esta é a impressão dada pelos jornais no início da década de 1930, a julgar pela facilidade com que a prefeitura destinava recursos para iluminação e decoração do percurso do desfile oficial, ao longo da Rua Chile, bem como proporcionava palcos, alto-falantes e decorações, em comparação com o grau em que eles arrastavam os pés para fazer o mesmo na Baixa dos Sapateiros, apesar da tradicional pretensão desta via de rivalizar com a Rua Chile. De fato, em 1940, a Baixa dos Sapateiros tinha caído tão fora das graças que não era mais parte do percurso do desfile oficial. ${ }^{28}$

${ }^{26}$ Os artigos nos jornais, durante todo o período, comentavam o crescimento e a diminuição do apoio do estado e principalmente do município para os grandes clubes. $\mathrm{O}$ orçamento municipal para 1939, o único ano disponível, indicava que em 1939 o Cruz Vermelha e o Fantoches da Euterpe receberam trinta contos de reis cada, enquanto o Inocentes em Progresso recebeu vinte contos de reis, uma quantia não insignificante naquele tempo. Arquivo Histórico Municipal de Salvador [daqui em diante, AHMS] Fundo Prefeitura Orçamento, Livro de orçamento de 1939.

${ }^{27}$ Cornélio Daltro de Azevedo para o prefeito de Salvador, 6 de julho de 1935, Pasta Clubes Carnavalescos, AHMS.

28 Ver, por exemplo, Diário de Notícias, 11 de fevereiro de 1939. Ver também a reportagem sobre a resposta sem entusiasmo do prefeito aos pedidos de apoio para o carnaval popular e predominantemente afro-baiano na praça do Terreiro de Jesus, em comparação com outras áreas da festa: A Tarde, 9 de fevereiro de 1933. 
Depois de 1937, a elite política do Estado Novo também apreciava as vantagens políticas de associar-se a um carnaval de sucesso. Embora pareça que tenha ela intensificado o apoio geral ao carnaval ao longo dos anos antes da Segunda Guerra Mundial, ainda se concentrava, no entanto, nos clubes de elite, como é ilustrado pelo fato de que em 1939 o interventor, o prefeito, o chefe da Secretaria de Segurança Pública e outros altos representantes e ideólogos do Estado Novo mantinham cargos honoríficos no quadro de diretores do clube carnavalesco Cruz Vermelha, de longe o de maior apelo popular entre os três clubes. ${ }^{29}$ Além disso, muitos baianos da classe trabalhadora, além de suas próprias instituições, também tinham fortes laços de lealdade a um ou outro clube de elite. ${ }^{30}$ Categorias profissionais inteiras podiam ser identificadas com um clube. Sapateiros, por exemplo, dizia-se serem adeptos do Cruz Vermelha. Consequentemente, essas alianças mitigavam a distância entre as elites e o resto de Salvador, e ambos refletiam e reforçavam os laços de clientelismo que estruturavam a hierarquia social da cidade. ${ }^{31}$ Os prefeitos, começando com Neves da Rocha, nomeado no início do Estado Novo (1938-1942), também se associavam às festividades, e de modo tão pessoal como presidir alguns momentos das festividades, como a cerimônia de coroação da Rainha do Carnaval. ${ }^{32}$

Não só a elite política, mas também os jornais e programas de rádio da década de 1930 apoiavam fortemente a ideia de que o carnaval de Salvador era amparado nos três clubes de elite. O padrão da cobertura jornalística era esmagadoramente voltado para as instituições e as atividades desses clubes, os seus carros alegóricos, desfiles e bailes, em cuja onipresente importância residia o coração do discurso da mídia em torno do carnaval, e cujos temas variavam desde referências ao mundo clássico, a Europa Ocidental, Ásia e Oriente Médio, e aos eventos brasileiros daquele momento. Seus temas quase nunca falavam diretamente da cultura da classe trabalhadora ou afro-baiana, antes do final de 1938, e o sociólogo norte-americano Donald Pierson registrou que "das

29 Diário de Notícias, 13 de fevereiro de 1939.

30 Donald Pierson, Negroes in Brazil, a Study of Race Contact at Bahia, Chicago: University of Chicago Press, 1942, p. 201, estava em Salvador em 1936 e nos conta que "a rivalidade especialmente entre o Cruz Vermelha e o Fantoshes [sic] é intensa, o Inocentes em Progresso é geralmente respeitado".

31 Diário de Notícias, 6 de fevereiro de 1937.

32 A Tarde, 24 de janeiro de 1942. 
168 mulheres jovens das melhores famílias da Bahia sobre os carros alegóricos no desfile de carnaval de 1936, todas eram brancas, com exceção de duas, e estas eram mulatas muito claras". ${ }^{33}$ Embora os pequenos clubes e eventos da classe trabalhadora muitas vezes se espremessem entre as grossas colunas dos grandes clubes, especialmente a partir de meados dos anos trinta, isto, pelo menos inicialmente, de fato só serviu para estabelecer o seu status marginal no discurso da mídia sobre o carnaval. Em suma, nesse momento, os três clubes de elite dominavam o carnaval de rua, como haviam feito, com breves interrupções, desde a década de 1880. Eles também arcavam com a responsabilidade financeira do espetáculo, embora a partir de 1935 tenham recebido subsídios dos cofres públicos para ajudar a aliviar os custos.

Isto não poderia durar para sempre, e 1937 foi o último ano, com uma exceção, em que os três grandes clubes desfilaram em cortejos separados. Em 1938, apenas o Cruz Vermelha, de longe o maior dos três, conseguiu participar. Eles ainda mantinham bailes e eventos, mas um desfile principal estava além de suas possibilidades. Os problemas financeiros tinham incapacitado os outros dois clubes. A depressão global tinha colocado uma enorme pressão sobre o crescimento econômico da Bahia, o que enfraqueceu a capacidade dos grandes clubes de desfilar seus tradicionais e luxuosos carros alegóricos. Apesar das promessas, em 1941, de um carnaval "guerra-relâmpago" pelo "assalto dos carros dos grandes clubes”, a Segunda Guerra Mundial findou a era dos grandes clubes, por várias razões. ${ }^{34}$ Embora o Brasil tenha-se mantido neutro até agosto de 1942, a guerra sufocou o ânimo do carnaval de rua. Festa pública na escala de anos anteriores não parecia muito apropriado. A guerra também impediu que os grandes clubes importassem os luxos necessários para as suas alegorias e fantasias, por falta de disponibilidade ou em razão dos preços elevados. Talvez a mais esmagadora razão foi que o conflito na Europa significou tempos de vacas magras para a oligarquia comercial da Bahia, para não mencionar a carência e o sofrimento dos pobres, que se prolongou até a década de 1950. Consequentemente, o carnaval de 1940 foi "quase bom", com os grandes clubes conseguindo combinar os seus esforços em um único

\footnotetext{
33 Pierson, Negroes in Brazil, pp. 202-3.

34 Diário de Notícias, 10 de janeiro de 1941.
} 
carro alegórico, que a imprensa devidamente louvou como um indicativo do espírito de cooperação de Salvador em tempo de guerra e sacrifício:

os baianos se uniram em uma frente única contra seus inimigos. ${ }^{35}$ Este, porém, foi o melhor que se conseguiu até as celebrações do "Carnaval da Vitória" em 1946. O carnaval em 1943 foi "muito, muito frio", com a maioria da festa acontecendo nos bailes nas sedes dos vários clubes ao redor da cidade. ${ }^{36}$ No ano seguinte, foi um "fracasso incontestável". ${ }^{37}$ Os três grandes clubes não conseguiram se reunir num cortejo associado entre 1941 e 1945, apesar de notícias ocasionais de que o fariam. O carnaval de rua foi efetivamente cancelado em 1945, e foi deixado aos pequenos clubes a realização de um carnaval como "ofensiva contra a infelicidade". 38

\section{A ascensão das batucadas}

O declínio dos clubes de elite criou um vácuo no qual os pequenos clubes se tornaram centrais para o carnaval baiano. Mesmo antes de 1938, o número, tamanho e iniciativa dos clubes menores já estavam alterando o equilíbrio do carnaval rumo ao popular. O Diário de Notícias iniciou a sua primeira competição para os pequenos clubes naquele ano, visto que eles estavam "mais animados este ano do que nunca" ${ }^{39} \mathrm{~A}$ década de 1940, por sua vez, viu triplicar o número de pequenos clubes participantes para bem mais de cem, transformando uma festa centrada na elite em um evento popular dominado quase que inteiramente pelos clubes pequenos.

A julgar pelas matérias de jornais relacionadas ao carnaval, esta foi a "Era das Batucadas", mas isso não poderia ter sido previsto duas décadas antes. As batucadas carnavalescas, para todos os intentos e propósitos, não existiam em Salvador antes de 1930. Em vez disso, Salvador ostentava inúmeros pequenos blocos e cordões com referências afrocêntricas em seus nomes, que, graças à iniciativa e ao protagonismo das classes trabalhadoras da cidade, proliferaram ao longo da década de

35 Diário de Notícias, 22 de fevereiro de 1941. Diário de Notícias, 3 de fevereiro de 1940; 7 de fevereiro de 1940.

${ }^{36}$ Diário de Notícias, 8 de março de 1943.

37 Diário de Notícias, 20 de fevereiro de 1944.

38 A Tarde, 1 de fevereiro de 1945, Diário de Notícias, 11 de fevereiro de 1945.

39 Diário de Notícias, 10 de janeiro de 1938. 
1920 (retomando onde haviam parado antes da proibição de clubes afrocêntricos entre 1905 e 1914). A reação nos jornais foi muito positiva, especialmente entre 1930 e 1934, quando os clubes de elite não conseguiram desfilar. Por conseguinte, os jornais abraçaram o "carnaval popular" e se entusiasmaram com todas as modalidades de pequenos clubes, incluindo aqueles intimamente associados com a cultura afrobaiana. ${ }^{40}$ Independentemente do pequeno número de batucadas e afoxés que estavam ativos, mas, majoritariamente anônimos, no início da década de 1930, encontramos blocos e cordões com nomes como Africanos em Pândega, Guerreiros da África, Filhos da África, Lordes Africanos, Ideal Africano e Gongo Africano. Temos até Pândegos da África, possivelmente uma homenagem a um dos primeiros clubes afrocêntricos da década de 1890. Em 1935, enquanto muito se fazia para o "renascimento" dos grandes clubes e seu desfile oficial, houve também um significativo alarde em relação ao desfile semi-oficial dos pequenos clubes, dos quais havia mais de 40, descritos como "grupos musicais, clubes, grupos africanos, cordões e batucadas". ${ }^{41}$

O surgimento das batucadas data do início ou meio dos anos 1930. A partir de 1935 os jornais começaram a distinguir as "batucadas", ao lado de blocos e cordões, praticamente pela primeira vez (ao lado de "escolas de samba", também). Este foi o primeiro ano em que isso foi feito de forma sistemática, marcando uma mudança não só de nomenclatura, mas também na prática do carnaval. Um tanto inexplicavelmente, grande parte dos blocos e cordões afrocêntricos - os "grupos africanos" - sumiram de vista. Em 1938, o grupo "A Negra Africana em Folia" foi o único vibrante o suficiente para aparecer nos jornais. Talvez muitos dos clubes afrocêntricos tenham se transformado em batucadas ou escolas de samba, ou permanecido como blocos ou cordões e mudado seus nomes para algo mais condizente com a tendência de fugir do afrocentrismo, talvez influenciados pelo exemplo dado no Rio de Janeiro. Hipoteticamente, por exemplo, "Guerreiros de África" pode ter se tornado uma escola de samba, tomando o nome de "Bambas da

${ }^{40}$ Interessante notar que, de acordo com Soihet, Subversão pelo riso, p. 58, antes de 1930, a imprensa no Rio de Janeiro raramente mencionava atividades na Praça Onze, que era o lugar principal das expressões culturais afro-cariocas durante o carnaval. Depois de 1930, no entanto, isso foi mudando gradativamente.

41 Para uma amostra, ver A Tarde, 2 de fevereiro de 1930; A Tarde, 4 de fevereiro de 1931; A Tarde, 25 de fevereiro de 1933. A Tarde, 1 de março de 1935. 
Zona" ou "Malandros da Avenida". Apoiando essa suposição, a cobertura jornalística geral, em 1935, incluiu uma grande afluência de nomes não listados previamente de todas as modalidades de pequenos clubes, não apenas "batucadas", e os membros dos clubes afrocêntricos também passaram a aderir a uma dessas outras modalidades . Certamente eles não "se aposentaram" do carnaval. Infelizmente, as reportagens nos jornais são demasiado vagas para termos essa certeza, e as entrevistas de história oral se revelaram inconclusivas. Não é provável que fosse qualquer tipo de autocensura do jornal relacionada com a ditadura do Estado Novo. Este aparente declínio dos cordões afrocêntricos ou afoxés também pode ter sido influenciado, como tanta coisa associada com o carnaval, por novas tendências culturais ou modas. Talvez a necessidade de afirmar uma herança africana tenha diminuído com uma maior aceitação das tradições culturais pelo interventor Juracy Magalhães, na Bahia (1930-1936) e por Vargas na cena nacional. ${ }^{42}$ Esta necessidade pode também ter sido preenchida pelas batucadas e escolas de samba emergentes, abraçadas como foram na capital do país. Também turva a situação o fato de que reportagens jornalísticas tendem a seguir atentamente as novidades mais do que as antigas práticas. Independentemente do motivo, no entanto, os antigos clubes afrocêntricos da classe trabalhadora, da década de 1920 e 1930, resultado normal da organização da comunidade e da identificação étnica no contexto pós-Abolição, claramente proporcionaram uma plataforma para o aumento das batucadas nas décadas de 1930 e 1940, que, por sua vez, devem ser debitadas a uma herança cultural africana e afro-mestiça, com as suas próprias instituições, particularmente aquelas associadas ao candomblé, que fizeram apenas concessões mínimas à cultura dominante, não obstante os laços de clientelismo com a classe média, geralmente mulata de pele clara. $^{43}$

A presença das batucadas no carnaval de Salvador, depois de 1930, cresceu a partir de tradições musicais locais. Salvador estava impregnada de precedentes locais de grupos de percussão, como os batuques dos séculos XVIII e XIX, um subgrupo específico de ritmos e danças com suas origens no contexto das culturas africana e afro-baiana do

${ }^{42}$ Para uma discussão do apoio de Magalhães à cultura negra, ver Ickes, African Bahian Culture and Regional Identity, capítulo 2.

43 Butler, Freedoms Given, Freedoms Won, pp. 184-5. 
Novo Mundo, dos quais as batucadas derivaram o seu nome. ${ }^{44}$ Salvador também ostentava precedentes de carnaval, como os afoxés do início do século XX e os cucumbis do século XIX, descritos por Nina Rodrigues, Arthur Ramos e outros, instituições que levavam africanos e afro-baianos e suas tradições culturais para as ruas durante o carnaval..$^{45}$ No entanto, o impulso para as batucadas do carnaval de Salvador veio das escolas de samba do Rio de Janeiro, da década de 1920, e da popularização do repinique ou tambor, um instrumento percussivo mais facilmente portátil que facilitou a mobilidade dos ritmistas do samba, condição sine-quanon para desfilar. Importante também foi a ascensão do nacionalismo cultural no Brasil e o consequente interesse pelos gêneros musicais regionais ou nacionais e pelos compositores locais de todos os matizes. Esta tendência foi assumida em Salvador com algum entusiasmo nos anos de 1920, e o samba afro-baiano, o batuque e a batucada foram seus beneficiários óbvios. É quase desnecessário dizer que, durante as décadas anteriores à Primeira República (1889-1930), qualquer forma pública do batuque ou batucada podia ser alvo de crítica pela classe dominante de Salvador, embora, como mencionado acima, nas décadas de 1910 e 1920, durante os primórdios do samba (e de seu predecessor, o maxixe), a popularidade destes gêneros, como as modas entre as elites (em seus clubes, concertos e bailes), tenha conhecido a ascensão e a queda.

Em 1937, nove diferentes batucadas foram mencionadas na cobertura jornalística do período anterior, e durante o próprio carnaval, representando cerca de um quarto de todos os pequenos clubes, cujo tipo (bloco, cordão etc.) pode ser identificado. Não está claro o que levava um pequeno clube a ser mencionado, embora geralmente os clubes maiores, mais ativos, fossem noticiados, ou aqueles que enviavam algum tipo de anúncio para os jornais. No entanto, uma avaliação da cobertura fornece uma ideia geral do aumento da participação das batucadas. Por exemplo, em 1948, vinte e uma diferentes batucadas ou escolas de samba foram mencionadas, o que representa pouco mais da metade do total verificado. ${ }^{46}$ Embora o número total de pequenos clu-

${ }^{44}$ Para batuque no pós-Abolição em Salvador, ver Fry et allii, "Negros e brancos", pp. 252-60.

45 Raymundo Nina Rodrigues, Os africanos no Brasil, São Paulo: Companhia Editora Nacional, 1977; Arthur Ramos, O folclore negro no Brasil, Rio de Janeiro: Civilização Brasileira, 1936; Alexandre José de Mello Morais, Festas e tradições populares do Brasil, Rio de Janeiro: Fauchon e Cia [1895], p. 76, 132.

${ }^{46}$ A Tarde, 20 de janeiro de 1951. 
bes tenha crescido rapidamente desde os anos de 1930, a taxa de crescimento das batucadas ultrapassou a dos blocos e cordões. Em 1951, vinte foram mencionados, depois o número se estabilizou e, a partir de então, começou a declinar. No entanto, em 1951, consta terem participado quarenta batucadas no "Desfile das Batucadas", por isso, embora ainda haja certa imprecisão na determinação do número absoluto e peso relativo da participação no carnaval baiano, quarenta batucadas foi significativo. Muitas destas não mencionadas na cobertura do carnaval seriam pequenas, de bairros periféricos, ou ambos.

As batucadas de Salvador, também apropriadamente conhecidas nos jornais como escolas de samba, eram na maioria das vezes totalmente masculinas, formadas por dez e vinte componentes com pronunciada influência e filiação à classe trabalhadora afro-baiana. Donald Pierson as descreveu como compostas por "invariavelmente negros ou mulatos escuros". ${ }^{47}$ Efetivamente, uma banda de percussão itinerante. As batucadas tinham como base a vizinhança, embora quaisquer vínculos associativos pudessem reunir músicos e foliões a partir de uma variedade de bairros ou ocupações. Os trajes ou uniformes eram o que implicava o maior gasto para os membros, mas também um ponto de orgulho. Cada indivíduo era responsável pela aquisição do tecido, contratava uma costureira ou fazia a sua própria costura. ${ }^{48}$ Como o nome batucadas indica, percussão e ritmos percussivos de samba eram particularmente o seu forte. Eles marchavam em fila única e tocavam os sucessos do momento, embora o estilo musical das batucadas fosse um tipo diferente da interpretação que se ouvia no rádio. Além disso, muitas batucadas tocavam músicas de sua própria criação. As batucadas, ou "sambas do morro", como eram também conhecidas na Bahia, eram muito mais cruas e menos melódicas, tornando a prática cultural afro-baiana mais próxima das tradições musicais das classes trabalhadoras e de trabalhadores pobres de Salvador. ${ }^{49}$

Dois exemplos de batucadas de 1948 ilustram as suas caracterís-

47 Pierson, Negroes in Brazil, p. 201.

${ }^{48}$ Luciano da Silva, entrevistado pelo autor, Salvador, 10 de novembro de 1999; Inail Alves, entrevistado pelo autor, Salvador, 18 de outubro de 1999.

49 Não muito tempo depois, quando as gravadoras começaram a profissionalizar compositores de samba para o mercado nacional, o nome "batucada" foi dados ao gênero de samba de ritmo animado e grande ênfase percussiva. 
ticas gerais. "Malandros em Folia" era da Roça do Lobo, no Tororó, e a "Escola de Samba Malandros do Amor", do Alto das Pombas, ambos os bairros eram operários. A informação descritiva vem do então não-oficial jornal do Partido Comunista da Bahia, O Momento. Durante a curta duração de sua vida legal (1945-1947), no clima de abertura democrática do imediato pós-guerra, o Partido Comunista, em Salvador, usou seu jornal para celebrar a cultura afro-baiana como parte de uma ênfase mais ampla na vida da classe trabalhadora. Depois que os comunistas brasileiros foram proibidos de concorrer a eleições em 1948, o jornal continuou a ser publicado. $O$ Momento, não por acaso, trazia noticias mais frequentes sobre as batucadas afro-baianas do que sobre blocos ou cordões, o que atesta a relevância das batucadas para os pobres e para a classe trabalhadora soteropolitana, e era um símbolo do seu engajamento no carnaval.

"Malandros em Folia" era composta por cerca de 10 homens, sete dançarinas, conhecidas como pastoras, duas porta-bandeiras e uma mascote. Seu líder era Otávio Neves de Jesus, apelidado de Dunga, um cabo de polícia e, de acordo com o jornal, um craque de um dos times de futebol locais, o Botafogo. O grupo escrevia seus próprios sambas, e os executava durante os ensaios atraindo os vizinhos às portas para assistir. Atraiu também a atenção de um repórter de $O$ Momento, que publicou uma das letra: "Nosso samba não pode parar / Se alguém vier nos desacatar / Damos couro até o sol raiar / Com Bia na cuíca / Bento no surdo e Balance/ Neves fazendo a marcação / A turma toda dá no couro / Para alegrar os corações". Neste ponto, cada um dos tocadores principais cantava sua própria parte. Bia, por exemplo, que tocava cuíca, cantava primeiro: "Fala cuíca malvada / Fala cuíca / No lugar que tem cuíca / Tamborim não vale nada." Então Balance cantava: "Crave o punhal no meu peito / Tire sangue e lave a mão / O relógio marca a hora / Da nossa separação". Por fim, Dunga cantava a letra que lembrava o nome do grupo: "Tenho direito de ser malandro / Mas não de ser um santo / Nossa Senhora lhe cubra / Com seu divino manto". ${ }^{50}$

Duas coisas se destacam aqui. A primeira é a referência temática ao malandro, o que nos lembra que os sambas tocados durante o carna-

50 O Momento, 5 de fevereiro de 1948. Embora, no Brasil, o Partido Comunista estivesse efetivamente na ilegalidade em 1947, O Momento continuou a ser publicado cada vez mais esporadicamente até 1957. 
val pelas batucadas eram muitas vezes mais ousados do que os tocados no rádio, especialmente após 1938, ou aqueles cujas letras eram impressas nos jornais na seção "Para você cantar". Esses sambas populares representavam também certo grau de assertividade rebelde em sua glorificação dos valores específicos do sexo masculino da classe trabalhadora e eram associados com o contexto socioeconômico do samba, valores não necessariamente compartilhados ou apreciados pela classe dominante. Também notável nas letras citadas acima é o prazer na execução, a assertiva autoconfiança e competitividade lúdica que podem ser tomados como características reinantes do carnaval popular de Salvador durante a era Vargas.

Uma segunda característica notável das letras, e ilustrada pela maioria das noticias sobre as batucadas, era a frequência com que eram improvisadas pelos grupos, ${ }^{51}$ muitas vezes uma dinâmica de samba de resposta. Essa natureza de improviso e flexibilidade significava que a letra poderia ser adaptada às circunstâncias, como quando "Malandros do Amor" procurou lisonjear o repórter de O Momento: "Você não está conhecendo / O repórter de O Momento / É quem anda lutando / Pra nos dar melhoramentos / Indicando o povo a se politizar". ${ }^{52} \mathrm{O}$ repórter pode ter instigado isso. Mesmo assim, os cantores de samba tinham claramente a habilidade de construir letras de improviso, ou o artifício do jornalista não teria tido o efeito desejado. Também se deve notar que as batucadas e outras associações carnavalescas populares pareciam felizes em participar de uma troca lúdica com repórteres de jornal. No caso das letras desta escola de samba, havia claras posições políticas em favor da classe trabalhadora e uma aberta filiação partidária, mas isso, obviamente, deve ser apreciado dentro do contexto da entrevista com $O$ Momento, o jornal do Partido Comunista.

\section{A política e a relação da mídia com as batucadas}

O aumento do número e da presença das batucadas, depois de 1935, não passou despercebido aos jornalistas da capital, os principais agentes pelos quais o carnaval de Salvador era definido, encorajado e noticia-

\footnotetext{
51 A Tarde, 17 de janeiro de 1949.

52 O Momento, 28 de janeiro de 1948.
} 
do. Enquanto os clubes de elite viam minguar sua fortuna, jornalistas e autores abraçavam e elevavam os pequenos clubes a novos símbolos do carnaval e expressões performativas e rituais de baianidade. E nisso eles reservavam um papel especial para as batucadas. Como associações esmagadoramente afro-baianas (em suas origens, composição demográfica e expressão cultural), as batucadas e a música percussiva que elas tocavam claramente estabeleceram um componente visual e sonoro afro-baiano do carnaval. Ao longo do período, este componente era cada vez mais incorporado nas celebrações do que seria "baiano" no carnaval de Salvador.

Os políticos do Estado Novo de Vargas demonstravam reconhecer a importância desses pequenos clubes e aumentavam seus subsídios, oferecendo uma variedade de prêmios em dinheiro para os vencedores nas numerosas competições desse grupo, bem como para a vencedora dos concursos de Rainha do Carnaval. Isso, pelo menos, permitiria a alguns clubes mais do que recuperar suas taxas de licenciamento, presumindo que eles as pagassem. Não há nenhuma indicação, no entanto, de que as subvenções tenham favorecido mais às batucadas do que aos blocos ou cordões. ${ }^{53}$ Certamente, os subsídios municipais não funcionaram como no Rio de Janeiro sob o primeiro governo de Vargas, tendo como alvo as escolas de samba e usados para institucionalizar os clubes e incentivá-los a apoiar as iniciativas culturais do regime, como a invocação de temas patrióticos. Em Salvador, a disseminação de mensagens políticas através do carnaval, via pequenos clubes, era difícil e pouco provável que fosse bem sucedida. Como descrito acima, os políticos do Estado Novo, em Salvador, quando lhes era dada a escolha, pareciam mais dispostos a alinhar-se com os clubes de elite, ou com a apresentação das rainhas do carnaval, e mesmo durante a ausência dos grandes clubes, na década de 1940, não há nenhuma evidência de que políticos tenham procurado associar-se especificamente com quaisquer clubes particulares de pequeno porte ou com um único gênero de clube. Isso teria sido um grau extremo do populismo (no contexto da Bahia), bem além de onde os representantes do Estado Novo na Bahia, ou seus sucessores imediatos, estavam dispostos a chegar. ${ }^{54}$

53 Diário de Notícias, 10 de fevereiro de 1941.

${ }^{54}$ Houve algumas tentativas do regime no poder, entre 1930 e 1954, de estabelecer controle político mais formal sobre o carnaval. Houve proibições a críticas às "autoridades federais, estaduais e 
Eleito pelo voto popular, o governador Otávio Mangabeira (19471951) também preferia associar-se com os clubes de elite, ou reunir-se e posar com a Rainha do Carnaval, como em 1951 (enquanto a Prefeitura patrocinava a competição oferecendo o seu próprio prêmio). ${ }^{55}$ No entanto, ele também era mais propenso do que seus antecessores a associar sua função pública aos pequenos clubes. Por exemplo, em 1949, Mangabeira não esteve apenas preocupado com o desfile central dos três grandes clubes, mas também "atravessou partes da cidade, onde o carnaval popular de rua acontece, confirmando a animação do povo". ${ }^{56}$ Em 1951, talvez em resposta ao seu reconhecimento do carnaval popular, quarenta e seis pequenos clubes participaram de um desfile de aquecimento para o carnaval, que foi também uma homenagem a Mangabeira, acenando lenços brancos ao passar pelo Palácio do Governo a fim de "saudá-lo". ${ }^{57}$ Sucessor imediato de Mangabeira, Regis Pacheco nunca pareceu muito interessado em qualquer uma das festas ou na cultura popular de Salvador. No entanto, o prefeito, José Wanderley de Araújo Pinho (1947-1951) e seus sucessores, particularmente Osvaldo Veloso Gordilho (1951-1954) e Aristóteles Góes (1954-1955), no exercício dos seus mandatos, apoiaram o carnaval e estiveram muito ocupados a assistir em uma miríade de eventos sociais relacionados ao carnaval, bem como a andar pelas ruas durante os dias da festa. O primeiro consistente subsídio municipal para os pequenos clubes começou com o prefeito Gordilho no início da década de 1950: a prefeitura distribuiu prêmios em dinheiro a cada um, e mesmo aos bem pequenos clubes que competiram nas principais etapas estabelecidas, no centro de cidade. ${ }^{58}$ Sobretudo, parece ter havido uma progressão em direção a um maior populismo nas relações políticas baianas e atenção ao carnaval popular, ao espetáculo e seus vínculos cada vez mais acentuados com a cultura afro-baiana.

municipais", bem como às associações e instituições militares e religiosas, e até mesmo a representações consulares durante o tempo da guerra. Houve também esforços locais para moralizar o comportamento no carnaval, especialmente o da classe operária, mediante restrições punitivas a bebidas alcoólicas e controle sobre jogos e uso de lança perfume, por exemplo. Ver as numerosas portarias em APEB, Secretaria de Segurança Pública, 1906-1943, Cx $6456 \mathrm{Pc}$ 03. Para informações adicionais sobre o relacionamento do carnaval com o estado, fora do âmbito da política cultural, ver Ickes, "Transformist Hegemony", capítulo 5.

${ }^{55}$ A Tarde, 16 de janeiro de 1951.

56 A Tarde, 28 de fevereiro de 1949.

${ }^{57}$ A Tarde, 31 de janeiro de 1951. A Tarde, 12 de janeiro de 1951.

58 Estado da Bahia, 23 de fevereiro de 1955. Estado da Bahia, 2 de fevereiro de 1952; A Tarde, 21 de janeiro de 1953. 
Ironicamente, foram os próprios clubes de elite que, durante o Estado Novo, sob certo aspecto, pressagiaram a nova ênfase na afrobaianidade no carnaval. O de 1940 foi proclamado o "Carnaval das baianas" e os clubes de elite, "inspirados pelo sucesso de Carmen Miranda", pediram às mulheres para ir aos bailes vestidas de "baiana". Clubes menores também realizaram bailes com base nesse tema, e até mesmo donas de pequenos negócios que operavam durante o carnaval foram exortadas a se vestir como tal. ${ }^{59}$ Com certeza, grande parte desta associação do carnaval com mulheres e samba afro-baianos foi feita através de paródia (na verdade, até mesmo uma paródia de uma paródia, dada a natureza jocosa do uso inicial por Carmen Miranda do traje de baiana). Além disso, no ano anterior, 1939, um dos carros alegóricos do Fantoches abordava a contribuição da mãe preta, ou ama de leite preta, para a civilização brasileira, o que, obviamente, aponta para os limites e critérios de inclusão de pessoas de ascendência africana nas mentes das elites locais. Um jornal não se esquivou da questão central, mas apontou que a babá simbolizava o servilismo passado e presente de muitas pessoas de cor no Brasil, um servilismo com base na raça que não tinha lugar no "momento atual, radiante de democracia e igualdade" ${ }^{60}$ No entanto, com a escolha da elite, em 1940, do "Carnaval das Baianas", podemos retrospectivamente ver que a associação do carnaval com cultura afro-baiana estava se tornando axiomática, enquanto o equilíbrio global dos significados discursivos do carnaval baiano inclinava em favor da cultura afro-baiana da cidade.

Isso não quer dizer que as contribuições da elite para o carnaval tenham caído em desgraça com a mídia. Mesmo após o desaparecimento dos desfiles dos clubes de elite, os jornais continuaram a divulgar e cobrir seus bailes e eventos carnavalescos. Durante o Estado Novo, revistas ilustradas locais, como Festa, que atendia à classe dominante e mediava os interesses desenvolvimentistas do regime de Vargas em Salvador, viam o carnaval a partir da perspectiva dos clubes de elite e estritamente dentro dos limites dos eventos ao longo da Rua Chile. ${ }^{61}$ No entanto, na grande imprensa, a partir do final dos anos 1930, as batucadas tornaram-se centrais para a construção discursiva do carnaval de

59 Diário de Notícias, 20 de janeiro de 1940, 3 de fevereiro de 1940.

${ }^{60}$ Diário de Notícias, 18 de fevereiro de 1939.

${ }^{61}$ Festa, ano 11, n. 6 (abril de 1941). 
Salvador. A Associação de Cronistas, em particular, abraçou esta mensagem. Esta associação, que incluia um ou dois jornalistas de cada um dos principais jornais da cidade (nos quais tinham suas colunas diárias de carnaval), passava a maior parte de janeiro e fevereiro e, por vezes, de março a organizar e incentivar a participação nos diversas bailes, ensaios e cerimônias que antecediam o carnaval. A Associação dos Cronistas de Carnaval assumiu a responsabilidade pela divulgação do carnaval, mobilizando a participação e a animação da festa, e como principais comentaristas dos acontecimentos, eram, portanto, participantes ativos na construção dos significados da festa para a cidade, fazendo isso de maneira a responder à dinâmica local, bem como ao contexto nacional. Os jornais se tornaram a fonte básica de concessões e prêmios durante o carnaval, ao lado da prefeitura, alavancando o apoio financeiro e, indiretamente, influenciando o desempenho do carnaval.

Durante anos, mesmo quando os blocos e cordões eram mais numerosos que as batucadas na cobertura total do carnaval, estas foram elevadas à representação mais autêntica do significado e natureza simbólica do carnaval de Salvador. Em várias ocasiões, os jornais também sugeriram que as batucadas eram as mais numerosas entre os pequenos clubes em toda a cidade. ${ }^{62}$ As rádios levavam escolas de samba e batucadas aos estúdios nas semanas que antecediam ao carnaval. Os programas de rádio, que apresentaram a "Escola de Samba Primeiro Nós", em 1937, e a batucada "Bambas da Zona", em 1939, ilustram como esses gêneros de pequenos clubes foram cada vez mais emblemáticos no carnaval. ${ }^{63}$ Seus repertórios diferiam do repertório das "bandas de jazz" dos últimos dez anos ou mais, que também tocavam sambas de vez em quando, mas com um repertório bem maior e muito mais variado, mesmo durante os eventos carnavalescos. Em 1937 e 1938, a Academia de Samba Deixa Falar (homônima baiana da primeira escola de samba no Rio de Janeiro) pegou uma onda de popularidade que ecoou através dos jornais e rádio. Eles não eram conhecidos apenas como bons músicos, parte de sua popularidade pode ter se originado do fato de que se gabavam de ter um presidente oriundo da classe média (afro-baiana), Ponciano Nonato de Carvalho, a quem os jornais se referiam como um

${ }^{62}$ Diário de Notícias, 22 de fevereiro de 1939.

${ }^{63}$ O Imparcial, 8 de janeiro de 1937; Diário de Notícias, 13 de fevereiro de 1939. 
negociante bem-quisto e que talvez tenha melhor entendido como se articular com a mídia e a indústria da música. ${ }^{64}$

A primeira aclamação da mídia e declaração da importância da cultura afro-brasileira no carnaval, e das batucadas em particular, veio de um artigo originário do Rio de Janeiro, mas reeditado em Salvador em julho de 1937. Este caiu muito bem, uma vez que a capital do país era uma influência importante sobre as tendências do carnaval na Bahia. $\mathrm{O}$ artigo era de Rubem Braga, autor de crônicas brasileiras, prestes a ser famoso. Braga disse explicitamente que, apesar do carnaval ser uma experiência cultural e racialmente mista, o pobre, e especialmente os negros pobres ("o elemento negro") eram os "leader" [sic] deste grupo que "realmente fazia o carnaval". Prosseguia a elogiar a singularidade cultural (e racial) e o poder da escola de samba e do samba de religar-se com as tradições religiosas afro-baianas. ${ }^{65}$ Esses sentimentos continuaram a encontrar expressão, em Salvador, no amplo discurso sobre o carnaval durante a Segunda Guerra Mundial. Isso acontecia nos editoriais e colunas sobre carnaval, como o que insistia que "Todos os baianos vão vibrar com os [...] alucinógenos ritmos das marchas e sambas" ${ }^{66}$ É interessante salientar que quando Áureo Contreiras (por exemplo, no texto que abre este artigo) acolheu "todos os instrumentos bárbaros evocativos do passado nas senzalas e nos terreiros", ele ainda usou a palavra "bárbaro", mas ela já não era inteiramente pejorativa. Depois de 1930, para muitos escritores, especialmente os modernistas, a palavra vinculava-se a contribuições positivas, ainda racista, é claro, mas denotava algo elementar e profundamente humano, primitivo até, adequado ao momento bacanalizado do carnaval, subvertendo a sofisticação e a reserva "burguesa". Na verdade, o samba e, especialmente, as batucadas - a forma crua e não retocada pelos estúdios de música expressavam que o carnaval baiano (e brasileiro) tinha de fato aquele elemento que fazia dele $\boldsymbol{o}$ carnaval. ${ }^{67}$

Não surpreende que numerosos sambas e batucadas fizessem referência a sua importância tanto para a baianidade quanto para o carnaval baiano. Em sua maioria eram criações da indústria da música cen-

\footnotetext{
${ }^{64}$ O Imparcial, 23 de janeiro de 1937.

${ }_{65}^{65}$ A Tarde, 26 de julho de 1937.

${ }_{66}^{6}$ Diário de Notícias, 3 de fevereiro de 1940.

${ }^{67}$ Mascarado II, "Carnaval no Uruguai”, Diário de Notícias, 9 de janeiro de 1954.
} 
tralizada no Rio de Janeiro, como as contribuições de Vicente Paiva, em 1940, "Bahia, oi... Bahia!" - "Depois de ouvir um samba / Que lá da Bahia vem / na voz da baiana bamba/ Que ginga como ninguém [...] Quem é que não gostaria de ser baiano também?”; ou a de 1943, "Exaltação à Bahia" - "Mas onde ela é mais Bahia / É no batuque e no samba" ${ }^{68}$ No entanto, muitos sambas locais, registrados nos jornais, eram voltados para temas como romance de carnaval, traição feminina ou dificuldades sociais, como a pobreza, em vez de temas ligados à cozinha afro-baiana ou ao candomblé. Em toda a série de 1953, seis composições locais (marchas e sambas), não houve uma única referência a cultura afro-baiana. ${ }^{69}$ No entanto, o emergente compositor e artista de rádio local Batatinha compôs, na década de 1950, pelo menos três sambas que faziam referência a cultura afro-baiana - "Iaiá não Samba", "Vatapá" e "Samba e Capoeira". Neste último, o samba explicitamente incorporou aspectos do estilo musical que acompanha a capoeira. ${ }^{70}$

Talvez o mais convincente, no entanto, um samba-batuque local bastante rústico de 1952, "A Bahia é terra boa”, mostra que a prática de incluir a cultura afro-baiana nas composições de samba e batucada estava firmemente enraizada, também, no próprio meio artístico soteropolitano. Há trechos de letras que expressam agressão e competição. Por exemplo, "A Bahia é terra boa / não inveja a ninguém", e "Bahia é combatida / Mas vencida não será “, ilustram a agressiva combatividade do gênero batucada em Salvador. Além disso, a batucada adota o mote da Bahia como a mãe do Brasil: "Se ela [Bahia] é mãe do Brasil / Que importa se falar "; e adota também a noção de democracia racial que vinha ganhando espaço no Brasil. Este último ponto é exemplificado na insistência de que a Bahia "ama aos filhos que são seus", incluindo

68 Vicente Paiva e Augusto Mesquita, "Bahia, oi... Bahia!", gravação original de Anjos do Inferno, Columbia, 1940. Vicente Paiva e Chianca de Garcia, "Exaltação à Bahia", gravação original de Heleninha Costa, Columbia, 1942. Para ver as letras, http:// cifrantiga3.blogspot.com/2006/08/bahia-oi-bahia.html, e http://cifrantiga3.blogspot.com/2006/ 05/exaltao-bahia.html.

69 Diário de Notícias, 8 de janeiro, 19 de janeiro, 22 de janeiro, 23 de janeiro, 25 de janeiro de 1953; ver também, para uma amostra, Diário de Notícias, 20 de janeiro de 1940; Estado da Bahia, 5 de fevereiro de 1947, 14 de janeiro de 1955. Para exemplos adicionais de letras de samba, ver Alessandra Carvalho da Cruz, "O samba na roda: samba e cultura popular em Salvador, 1937-1954" (Dissertação de Mestrado, Universidade Federal da Bahia, 2006), capítulo 4.

70 "Batatinha", Enciclopédia Nordeste, http://www.onordeste.com/onordeste/ enciclopediaNordeste/index.php?titulo=Batata\&ltr=b\&id_perso $=570$. 
"brancos" e "loiras". Não era apenas diversidade racial que a Bahia tinha, no entanto. A Bahia tinha cultura também. As batucadas empregavam alegorias que associavam a Bahia com a cultura negra, a "Baiana", que "faz batuque", que "mexe o caruru". 71

A importância das batucadas para a baianidade também era comum nos artigos mais lúdicos ou peças produzidas pelos jornalistas. Por exemplo, dois poemas publicados em A Tarde, no final de 1940, escritos por Sílvio Valente (um dos cronistas do carnaval, também conhecido como Pepino Longo), expressam a noção de que a batucada era o ponto de referência musical e o coração da folia popular. Nas linhas do poema "Evoé", Sílvio Valente comentava a forma como "A Batucada gostosa / Faz uma morena tão prosa / Cair no santo e sambar". ${ }^{72}$ Valente estava sublinhando a importância das batucadas afro-baianas para o carnaval (e indiretamente os supostos afro-baianos que tocavam nas batucadas), que animavam a morena "prosa" de pele mais clara para a vida. A menção ao transe, característico do culto do candomblé, aprofundava a associação de carnaval com a cultura afro-baiana.

Entretanto, Valente também tocou nos, não tão sutis, estereótipos raciais e culturais do período, embora ele o tenha feito de uma forma que celebrava a contribuição cultural dos afro-baianos. $\mathrm{O}$ autor distingue três categorias: a loira, a morena (de ascendência predominantemente europeia) e a mulata: "Vivam a loura e a mulata / De sandália de alpercata / E a morena que é meu bem!" Os versos, "Não façamos distinções / Como as 'unidas' Nações", referendando a suposta falta de discriminação racial no Brasil, o que tornava possível momentos como o carnaval. Vemos os mesmos sentimentos em uma estrofe do segundo poema de Valente, "Carnaval", do mesmo período. ${ }^{73}$ Era o poder universal da música a animar o "passar das batucadas" que criava a igualdade na folia entre as "classes fraternizadas" e permitia a "brancos, pretos, mulatos" sentir-se "todos irmãos". Era também "a alma da raça noturna” (presumivelmente afro-baianos) que estava no centro de im-

${ }_{71}$ Pedro Caldas, "A Bahia é terra boa”, Estado da Bahia, 13 de fevereiro de 1952.

72 A Tarde, 9 de fevereiro de 1948, citado em Leal, Pergunte ao seu avô, 174-75.

73 A Tarde, 28 de fevereiro de 1949, citado em Leal, Pergunte ao seu avô, 176-79. Ao passar das batucadas/batendo forte o tambor/as classes fraternizadas/se encontram no mesmo ardor/Nessa cadência soturna/a alma da raça noturna/eleva clamores vôos/E brancos, pretos, mulatos/ seguindo os passos exatos/se sentem todos irmãos/Louras, morenas, mulatas/De sandália e alpercata/Sambando no coração! 
portância do carnaval. Afinal, as batucadas emprestaram sua alma afrobaiana para o carnaval de tal forma a transformá-lo em um momento transcendente da igualdade racial nos trópicos: "Louras e morenas, mulatas / De sandália e alpercata / Sambando no coração!"

Valente não era o único jornalista a situar as batucadas e o carnaval da Bahia nos discursos mais amplo da lendária democracia racial e da identidade nacional do Brasil, ambos ganhando corpo durante este período, já que intelectuais do sudeste "elogiavam o samba como a música mais autenticamente nativa do Brasil" e retratavam as escolas de samba do Rio de Janeiro como a fusão das três raças. ${ }^{74}$ Jornalistas e escritores baianos, em especial após 1940, interpretavam a experiência do carnaval da Bahia, neste contexto do Brasil, como um produto da mistura racial e cultural e viam a "confraternização" das raças, durante o carnaval, como evidência de que o racismo não existia no Brasil. A popularidade deste expediente é parcialmente explicada pela guerra, que permitiu e incentivou um discurso patriótico de convivência mais inclusivo. De acordo com essas reportagens, o carnaval era uma época em que "a igualdade de raça e cor se torna realidade por 72 horas", e "ninguém está preocupado com quem é o próximo, qual é a cor de sua pele, ou se são de respeitável posição social. Todo mundo se acha igual" ${ }^{75}$

O gênero batucada, nas mãos da classe trabalhadora soteropolitana, também se prestou a momentos de afirmação cultural e racial. Digno de nota nesse sentido era um bloco chamado "Preto não é mais lacaio". Esses trezentos e cinquenta ou mais trabalhadores do bairro da Liberdade tiraram o nome do samba "Salve a Princesa [Isabel]". ${ }^{76} \mathrm{~A}$ letra do samba é reveladora. "Preto não é mais lacaio / Preto não tem mais senhor / ... / Hoje preto pode ser doutor / Deputado e senador". ${ }^{77}$

74 Raphael, "Samba Schools", p. 261. Queiroz, Carnaval brasileiro, pp. 58-9.

75 Fry et alli, "Negros e brancos", p. 235. Diário de Notícias, 4 de fevereiro de 1944, 13 de fevereiro de 1944. Na cobertura do carnaval, o ano em que a democracia racial é mais explícita é 1944, especialmente no Diário de Notícias, 4 de fevereiro ("a festa anula o preconceito"), 13 de fevereiro (carnaval tem pelo menos uma virtude, de "efetuar uma real igualdade de raças") e 20 de fevereiro.

${ }^{76}$ Francisco da Silva Fárrea Júnior e Luís Soberano, "Salve a Princesa", gravação original do Trio de Ouro, Odeon, 1948.

77 O Momento, 1 de fevereiro de 1948. Havia também um bloco na Bahia chamado "Preto não é mais lacaio" no final dos anos 1940. Vale a pena notar um fenômeno paralelo no Rio de Janeiro, também na década de 1940, como o clube carnavalesco "Unidos da Tijuca" expressava um politizado orgulho racial afro-brasileiro e leituras alternativas do mito da democracia racial em seus trajes carnavalescos e carros alegóricos: Tupy, Carnavais de Guerra, pp. 112-3. 
Este é um dos aspectos mais interessantes do mito da democracia racial. Nem os membros da batucada, nem o repórter de um jornal comunista que cobria sua história eram propensos a acreditar que a discriminação racial era inexistente no Brasil. Mas a ideologia da democracia racial (tanto a oficial quanto a do senso comum) colocou as pessoas de cor numa cabeça-de-ponte retórica a partir da qual podiam criticar a discriminação e a desigualdade existentes. ${ }^{78}$

No final da década de 1940, e durante a de 1950, os três clubes de elite lutavam para reviver a sua posição de domínio do evento festivo, e em 1951 a correspondência entre os clubes e o gabinete do prefeito, assim como a cobertura nos jornais, revelam que a prefeitura retomou seu antigo papel de subsidiar fortemente esses clubes. ${ }^{79}$ Isto incluia também a ajuda ocasional do governo do estado, o que levou a um renascimento de seus desfiles e de sua posição central no carnaval e no discurso sobre carnaval. ${ }^{80}$ Também a partir de 1950 , o foco da mídia na importância das batucadas para o carnaval estabilizou e começou a recuar. Mesmo assim, embora a cobertura diária do carnaval estivesse menos focada nas batucadas (na medida em que os clubes de elite e, em seguida, o trio elétrico atraíam a maioria das atenções dos jornalistas), elas eram ainda apresentadas como característica central do carnaval da classe trabalhadora nos crescentes subúrbios da cidade, e fizeram seu próprio desfile em separado. ${ }^{81} \mathrm{O}$ Estado da Bahia prestou homenagem ao bairro da Liberdade, com seu "maior número de batucadas, cordões e ranchos", publicando as letras de compositores locais que salientavam que "a turma da Liberdade... sabe batucar". ${ }^{82}$ Enquanto isso, o carnaval no bairro do Uruguai foi aberto com "clarins", que deram lugar à "cadência rítmica" e "ritmos primitivos" das batucadas que desencadearam a "animação quase primitiva" das festividades e o "entusiasmo natural dos nossos pobres". ${ }^{83}$

78 Paulina Alberto, Terms of Inclusion: Black Intellectuals in Twentieth-Century Brazil, Chapel Hill: University of North Carolina Press, 2011, p. 179; Alejandro de la Fuente, A Nation for All: Race, Inequality, and Politics in Twentieth-Century Cuba, Chapel Hill: University of North Carolina Press, 2001.

79 "Haverá préstito", Diário de Notícias, 25 de janeiro de 1950; "Ainda o préstito", A Tarde, 20 de janeiro de 1951. AHMS, Caixa "Clubes Carnavalescos e Esportivos".

80 "Será oficializado", A Tarde, 7 de fevereiro de 1951. Cabocolinho de Najé, "Nos barracões dos clubes", Estado da Bahia, 17 de fevereiro de 1955.

81 "Desfile de batucadas", A Tarde, 20 de janeiro de 1951.

82 "Homenagem à Liberdade", Estado da Bahia, 28 de janeiro de 1955.

83 Diário de Notícias, 9 de janeiro de 1954. Ver também, A Tarde, 19 de fevereiro de 1954. 
O declínio da atenção aos pequenos clubes, e batucadas em particular, foi parcialmente compensado em outras áreas da mídia impressa, como editoriais e especialmente os suplementos de cultura e literatura, que haviam se tornado os árbitros do gosto cultural no Brasil após a Segunda Guerra Mundial. Por exemplo, em 1949, o jornalista e intelectual modernista Cláudio Tavares publicou um artigo, no Estado da Bahia, acompanhado com fotos de Pierre Verger, em que tratou mais detalhadamente das "rodas de samba na Bahia". No artigo, originalmente publicado no mesmo ano na revista mensal brasileira A Cigarra, Tavares discutia, de forma mais ampla, as origens e a história do samba, bem como suas diferentes características e importância para afro-baianos e para a Bahia. ${ }^{84}$ Anos depois, um editorial de 1953 no Diário de Notícias, associava não apenas a cultura afro-baiana, mas também noções vagas de afro-baianidade (ou "negritude") com o carnaval, lembrando aos leitores que "os brancos seguiram os passos das pessoas de cor", até mesmo assumindo a prática de religiões afro-baianas. ${ }^{85}$ Finalmente, em 1954, a cobertura do carnaval incluia poesias com referências enaltecedoras à cultura afro-baiana. No poema "Carnaval" de Laurindo de Brito, os versos "carnaval negro da morte" e "sambas macabros dos vermes" precisam ser lidos no contexto de exaltação poética de um mundo virado de cabeça para baixo, excessivamente alucinógeno, erotizado e anárquico. O poema de Milton Costa Lima, no entanto, era muito mais literal no seu abraço às contribuições das festividades populares para o carnaval baiano, ou seja, a dança do samba e os tambores primordiais das batucadas. ${ }^{86}$

A desaceleração progressiva da "Era das Batucadas" aconteceu a partir dos anos 1950, embora as batucadas tenham permanecido um traço consistentemente popular do carnaval baiano até $1960 .{ }^{87}$ Este enfraquecimento se deveu a vários fatores. Em primeiro lugar, os clubes do carnaval de elite voltaram a receber subsídios. Quando o Estado da Bahia escreveu, em 1952, que "a participação dos grandes clubes era inteiramente de responsabilidade do governo" não estava exagerando.

${ }^{84}$ Cláudio Tavares, “As rodas de samba na Bahia,” Estado da Bahia, 29 de março de 1949.

85 Diário de Notícias, 21 de janeiro de 1953.

${ }^{86}$ Lima, "Meu Carnaval da Bahia," A Tarde, 25 de fevereiro de 1954; De Brito, "Carnaval," A Tarde, 25 de fevereiro de 1954.

87 Goli Guerreiro, "As trilhas do samba-reggae: a invenção de um ritmo", Latin American Music Review, v. 20, n. 1 (1999), pp. 120-22. 
A generosidade financeira do prefeito Oswaldo Gordilho era essencial e revela o quão importante ele sentia que os grandes clubes eram para o carnaval. ${ }^{88}$ Havia ainda alguns outros clubes da classe dominante na competição: o Democrata e o Espanhol, ambos fundados em 1946. Enquanto isso, o Yacht Clube, o Clube Baiano de Tênis e a Associação Atlética da Bahia, todos com associados abastados ou quase, também começaram a organizar bailes e carros alegóricos para o desfile. Além da revitalização dessa competição, as batucadas também sofreram devido a mudanças importantes no carnaval. A chegada do trio elétrico, cujo número se multiplicaria e que se tornaria uma figura definidora do carnaval baiano na década seguinte, talvez tenha chamado a atenção popular para longe das batucadas e solapado a sua energia. Também é possível, como um entrevistado salientou, que na década de 1950 as batucadas cobrassem preços fora da realidade, e que seus membros quisessem ou sentissem necessidade de se vestir com roupas cada vez mais caras. ${ }^{89}$ Novos cordões substituíram as minguantes batucadas, eles eram mais baratos, maiores e proporcionavam mais liberdade de ação, como não ter que desfilar em fila única, ou mesmo manter um ritmo. Sabemos, também, que duas outras tendências carnavalescas, a dos blocos de índios, ou grupos vestidos como apaches, sioux, tupi-guarani etc., e a versão mais recente das escolas de samba (embora ainda muito diferentes daqueles do Rio de Janeiro), surgiram nos mesmos bairros, na sua maioria na década de 1960, dentro do mesmo grupo demográfico das batucadas. ${ }^{90}$

\section{A adoção controlada e limitada da cultura afro-baiana}

O aumento das batucadas e sua celebração discursiva pela cultura dominante e a crescente associação do carnaval baiano com a cultura negra foram parte de uma ampla revalorização dos afro-baianos e suas contribuições para a baianidade depois de 1930. No entanto, a inclusão

${ }^{88}$ Estado da Bahia, 2 de fevereiro de 1952. Ver também os documentos em AHMS, Caixa "Clubes Carnavalescos e Esportivos".

89 José Ferreira, entrevistado pelo autor, Salvador, 11 de novembro de 1999.

${ }^{90}$ Fred de Goés, 50 anos do trio elétrico, Salvador: Corrupio, 2000. José Ferreira, entrevistado pelo autor, Salvador, 11 de novembro de 1999. Guerreiro, "Trilhas do samba-reggae, pp. 12022;" Antônio dos Santos Godi, "De índio a negro, ou o reverso", Caderno CRH (suplemento) (1991), pp. 51-70. 
performativa e discursiva dos afro-baianos no carnaval ocorreu de modo a ficar contida dentro de limites e valorizações hierárquicas muito bem definidos. Talvez um pouco surpreendente, dada a reputação do carnaval de ignorar a moralidade e a convenção social, os festejos de carnaval, em Salvador em particular, mantiveram graus muito significativos de separação racial e de classe. Por exemplo, o sociólogo norte-americano Donald Pierson escreveu sobre o Carnaval, em 1936, que

precedendo, durante e após o desfile [dos três grandes clubes] as batucadas e cordões negros passam através das multidões circulantes. As batucadas são geralmente compostas por quinze a vinte homens jovens, invariavelmente negros ou mulatos escuros.

Em uma pesquisa com

9 batucadas, de um total de 157 jovens, 113, ou 72 por cento, eram negros; 40, ou 25,5 por cento, mulatos, todos escuros, exceto um (que, apesar da pele clara, tinha cabelos crespos); 3 eram cafuzos [combinação de índio brasileiro com afrodescendente], e apenas 1 era branco. ${ }^{91}$

No extremo oposto deste espectro estavam os clubes de elite. O entrevistado José Ferreira foi rápido em confirmar com pouco ou nenhum exagero, que "quando o [clube de carnaval] Fantoches da Euterpe desfilava, não havia negros, não se via um único afro-baiano". ${ }^{92} \mathrm{Na}$ verdade, mesmo quando os carros alegóricos representavam uma cena de cultura afro-baiana usavam maquiagem preta no rosto . Em 1955, para seu principal carro alegórico, o clube carnavalesco de elite Cruzeiro da Victoria criou uma modesta homenagem à Abolição da escravatura, com doze "senhorinhas da nossa melhor sociedade" vestidas de baianas, com rostos escurecidos e grilhões quebrados pendurados em seus pul$\operatorname{sos}^{93}$

A partir desta evidência, ficam claras, na organização e experiência do carnaval baiano, profundas divisões ao longo de linhas raciais,

91 Pierson, Negroes in Brazil, pp. 201-02.

92 Pierson, Negroes in Brazil, capítulos 1-5, passim, tem algumas excelentes passagens anedóticas sobre suposições raciais e racistas entre os brancos baianos. José Ferreira, entrevistado pelo autor, Salvador, 4 de novembro de1999. Uma fotografia, de 1949, de 14 membros da "ala feminina" do clube de elite Inocentes em Progresso revela somente cútis claras: A Tarde, 22 de fevereiro de 1949.

93 Estado da Bahia, 19 de fevereiro de 1955. 
culturais e de classe. Além disso, pode-se recorrer a provas fotográficas nos jornais de meados a fins de 1940. Quase sem exceção, os blocos e cordões fotografados eram compostos ou de pessoas de ascendência predominantemente europeia, com alguns de ascendência mestiça de pele clara, ou eram esmagadoramente afro-brasileiros, com alguns de ascendência mestiça, mas com pele escura. Especificamente, as batucadas e afoxés capturados nas fotografias foram sempre inteiramente afrobrasileiros. Há também as fotografias de um pequeno número de blocos e cordões tiradas por Pierre Verger no final da década de 1940 e nos anos 1950. Estas também apresentam graus acentuados de homogeneidade racial dentro dos pequenos clubes de carnaval de Salvador. ${ }^{94}$ Fotografias do bloco de 80 remadores do Santa Cruz Sporting Clube, em Salvador na década de 1940, mostram seus membros totalmente de pele clara. Isso era típico da classe dominante ou de clubes desportivos de elite que, de acordo com um ex-membro e sua esposa, "não queriam pessoas com pele escura". ${ }^{95}$ Com relação às festas mais informais, Pierson reconheceu exceções, mas salienta que, mesmo em circunstâncias informais, pessoas de diferentes "raças" pouco se misturavam. Considerando as multidões de espectadores, Pierson teve a dizer que:

numa multidão circulando, dançando, cantando, normalmente se vê os brancos com brancos, negros e mulatos escuros com os negros e mulatos escuros, a exceção sendo que um branco, ocasionalmente, acompanha um grupo de mulatos escuros e negros, embora brancos da Bahia e mulatos claros sejam frequentemente vistos com os brancos.

Diferenças óbvias de posições sociais eram operadas durante o carnaval. Na verdade, os ricos participavam de maneiras muito diferentes daquela da classe operária ou dos trabalhadores pobres, o que significava, também, que as experiências de brancos e negros divergiam significativamente. Os cortejos dos grandes clubes de elite, por exemplo, eram símbolos claros de superioridade racial e de classe, e embora

${ }^{94}$ Pierre Verger, Retratos da Bahia, Salvador: Corrupio, 2002, pp. 122-35. Ver por exemplo fotografias do grupo carnavalesco "Embaixada Mexicana", também on line em pierreverger.org. Havia experiências de integração no carnaval, com certeza, em certos blocos ou cordões, por exemplo. Também, havia áreas públicas que abrigavam significativa mistura de participantes ou espectadores. Fotos do carnaval da Bahia, feitas por Pierre Verger no fim dos anos 1950, por exemplo, mostram pessoas de todos os tipos físicos em áreas adjacentes à rota oficial do desfile, como a Praça da Sé: Verger, Retratos da Bahia, pp. 122-24.

95 Walkyrio Meyer e Delza Meyer, entrevistados pelo autor, Salvador, 21 de outubro de 1999. 
a classe trabalhadora pudesse reivindicar fidelidade a um clube ou outro, sua relação com eles durante o carnaval era basicamente de espectadores. Batalhas de confetes e bailes à fantasia da classe dominante eram, em geral, inacessíveis para a maior parte da sociedade e para a maioria dos afro-baianos. Como entrevistada, Antônia Conceição afirmou que quando pessoas de ascendência africana eram aceitas em instituições de elite, a classe dominante era "muito exigente". Era possível para uma pessoa ou família negra estar presente em eventos na Associação Atlética da Bahia, por exemplo, mas somente se fosse uma formatura, "algo muito incomum". 96

Um artigo n'O Imparcial sugere que, mesmo em 1937, a Rua Chile, a arena principal do carnaval formal e rota do principal préstito dos grandes clubes, não era um espaço totalmente igualitário, visto que a polícia disse ter desmantelado uma roda de samba por lá. O Imparcial não defendeu nem criticou os sambistas, atitude típica de um momento em que o lugar do samba no carnaval de Salvador ainda estava em processo de se tornar central. O tom era de lamento imparcial de que "samba é pro Terreiro", significando que o Terreiro de Jesus era o lugar legítimo para tais práticas, uma vez que era visto como espaço da classe trabalhadora, onde afro-baianos celebravam o carnaval. O jornal não parece ter-se importado com o fato de que os músicos responsáveis eram do localmente famoso grupo "Três e Meio", que estava naquele tempo fazendo audiências em rádios locais em Salvador. O conteúdo das reportagens dos jornais, especialmente na década de 1930, reforça a ideia de que o Terreiro de Jesus, e não a Rua Chile, era o epicentro da prática popular e afro-baiana do carnaval, "o ponto de encontro das batucadas e dos afoxés" durante festas de Salvador, festas que se espalhavam pelos bairros pobres e da classe trabalhadora e ao longo da Baixa dos Sapateiros, mas não ao longo da Rua Chile, ou pelo menos não sem provocar algum grau de tensão racial e de classe. ${ }^{97}$

Mesmo a ascensão do samba como símbolo regional e nacional teve seus críticos influentes e declarados. Em 1937, professor emérito

96 Antônia Conceição, entrevistada pelo autor, Salvador, 2 de novembro de 1999.

97 O Imparcial, 11 de fevereiro de 1937; Leal, Pergunte ao seu avô, pp. 205-06. Para exemplos adicionais de sambas em horas e lugares "errados", e mesmo para uma sugestão de que o samba afeta a produtividade do trabalhador, ver, A Tarde, 18 de maio de 1946, 4 de dezembro de 1947, citado em Cruz, "Samba", p. 43. Ver também, A Tarde, 19 de março de 1935. 
da Faculdade de Medicina da Bahia, Luís Pinto de Carvalho, criticou as elites regionais e nacionais, incluindo o presidente Getúlio Vargas, por celebrar formas musicais populares como o samba. Pinto de Carvalho insistia que o único material adequado para a educação musical, bem como para o desenvolvimento artístico em geral, e até mesmo o bemestar social, era a música clássica. ${ }^{98}$ Quantos baianos podem ter concordado com o bom professor não é possível saber, mas sua posição no mínimo representava um discurso alternativo da classe dominante sobre o samba. Ecoando os sentimentos de Pinto de Carvalho, em 1937, o historiador e diretor da Faculdade de Direito, Pedro Calmon, criticou o samba como um gênero musical inadequado para representar o Brasil internacionalmente. Seu alvo era especificamente Carmen Miranda e suas "vulgares e degradantes" performances no exterior, apesar de sua crítica ter sido dirigida também a associação entre o Brasil e os negros da Guiné "ou hotentotes de camisas listradas". ${ }^{99}$ Como sugerem esses comentários, a associação do carnaval baiano com práticas afro-baianas foi acompanhada por um grau de criticismo. Estas críticas eram parte do processo de limitar e controlar os significados da cultura afro-baiana na medida em que eram assimilados como ideias de baianidade. Claramente, o carnaval, apesar de seu poder de aumentar a associação entre a Bahia e a cultura afro-baiana, não enfraqueceu as estruturas que regem as vidas diárias dos pobres e da classe trabalhadora em Salvador. Principalmente, o carnaval serviu para reforçar e legitimar as hierarquias socioeconômicas e raciais. A realidade de que o carnaval também era na prática uma performance da diferença racial e de classe revela as limitações para a aceitação de práticas afro-baianas em Salvador.

\section{Conclusão}

No entanto, uma mudança realmente ocorreu nas décadas de 1930 e 1940, e as batucadas estavam na vanguarda dessa mudança. As décadas de 1930 e 1940 merecem a sua designação de Era das Batucadas e o período deve ser entendido como um elo na trajetória histórica do car-

98 "Originalidades", O Imparcial, 10 de março de 1937; "Opiniões musicais", O Imparcial, 17 de março de 1937, discutido em Cruz, "Samba", pp. 44-8.

99 Pedro Calmon, "O Sr. José Lins é a favor do samba", Estado da Bahia, 15 de julho de 1937. Ver também, Bryan McCann, Hello, Hello Brazil: Popular Music in the Making of Modern Brazil, Durham: Duke University Press, 2004, pp. 63-5. 
naval baiano entre os afoxés de finais do século XIX e o dinamismo dos blocos afros da década de 1970. As batucadas desempenharam um papel vital no surgimento da indelével associação de Salvador com a cultura afro-baiana. O fundamental do desenvolvimento do carnaval da Bahia, de 1930 a 1950, foi que "a arte e o luxo" dos clubes de elite deram lugar a "batucada e animação" das escolas de samba de Salvador. ${ }^{100}$ A estagnação da economia da região e a Segunda Guerra Mundial minaram a saúde financeira dos clubes de elite e a vontade da prefeitura de subsidiá-los, e, portanto, a capacidade de desfilar seus cortejos individuais e manter o seu lugar central nas comemorações do carnaval da cidade. Enquanto isso, ao longo da década de 1930, e no pós-guerra especialmente, a classe trabalhadora pobre e afro-baiana de Salvador foi formando mais e mais batucadas para os três dias da festa que antecedem a quaresma. Jornalistas baianos também foram influenciados pela elevação do samba a destaque nacional na idealização das batucadas de Salvador como contribuições positivas para o carnaval da cidade, já que o samba era o gênero de música associado com as batucadas. $\mathrm{O}$ fenômeno das batucadas reforçou a tendência geral na Bahia, a partir de 1930, de jornalistas, acadêmicos, intelectuais e figuras públicas incorporar formas culturais afro-baianas como contribuições positivas e um elemento central da baianidade e da identidade regional baiana.

Embora os aspectos do carnaval que não eram especificamente identificados com a cultura afro-baiana ainda recebessem a maior parte da cobertura no carnaval, as batucadas revelaram as contribuições do protagonismo e da performance afro-baianos e desempenharam um papel significativo na transformação discursiva da identidade regional baiana. Durante a década de 1930, o carnaval de Salvador começou um reequilíbrio em favor dos pequenos clubes, um reequilíbrio que se intensificou com o surgimento das batucadas, uma fase em que o carnaval, o mais simbolicamente representativo das festas populares, tornouse profundamente associado com a cultura afro-baiana, na medida que essas práticas passaram de um discurso anterior de marginalidade para o de inclusão e ocasional celebração como a verdadeira alma do carna-

${ }^{100} \mathrm{O}$ citado contraste entre luxo e batucadas vem da comparação, feita por um entrevistado anônimo, entre Salvador e o Rio de Janeiro no Diário de Notícias, 10 de fevereiro de 1937. Ver Queiroz, Carnaval, p. 18, sobre um processo similar, mutatis mutanti, ocorrido no carnaval de São Paulo. 
val. Mesmo a crítica ocasional da mídia ao carnaval, ecoando as alas mais conservadoras da classe dominante, já não se referiam de forma negativa, ainda que eufemisticamente, a qualquer coisa que pudesse ser interpretada como afro-baiana. Em vez disso, a crítica se restringiu a lamentar a sua permissividade sexual, a sua afronta à honra da família e à moralidade em geral, seu materialismo, ou sua inadequação ao contexto das dificuldades econômicas. ${ }^{101}$

Que as práticas afro-baianas não tenham se tornado o principal, ou mesmo o único aspecto definidor do carnaval de Salvador, como foi o caso das escolas de samba do Rio de Janeiro, se deve a vários fatores. Enquanto no Rio de Janeiro chefes políticos locais reconheceram a utilidade política das escolas de samba, para as elites de Salvador parece não ter havido nem necessidade nem desejo de institucionalizar as diversas e instáveis pequenas associações de carnaval do redor da cidade. Em vez da institucionalização, as batucadas foram assumidas abstratamente como um gênero e fundidas no discurso e no conjunto de associações identificadas com a Bahia e o carnaval. O governo municipal concentrou suas energias e apoio financeiro nos três grandes clubes, e foi fundamental para sua revitalização no início da década de 1950. No entanto, a prefeitura também investiu recursos significativos para apoiar o carnaval popular e os clubes menores, não só no centro da cidade, mas também em numerosos pontos periféricos de maior animação . O prefeito Aristóteles Góes (1954-1955) fazia questão de participar não só dos bailes de elite, mas também de sair às ruas durante o carnaval popular. As batucadas, certamente, se beneficiaram disso e a mensagem era que o carnaval baiano continuaria a ser de elite e popular. Isso era conhecido na época como "oficialização do Carnaval", pois tanto a elite quanto a forma mais significativa de participação popular nas festas tornaram-se dependentes, ou pelo menos fortemente influenciadas, pela generosidade do governo. ${ }^{102}$

A revitalização dos grandes clubes, ao longo da década de 1950, significou o fim da "Era das Batucadas". Este fim foi ainda mais "cimentado" pela emergência, depois de 1951, do trio elétrico. ${ }^{103}$ A inovação gradualmente ganhou popularidade. Já em 1955, houve um segun-

\footnotetext{
${ }^{101}$ Ver, por exemplo, Diário de Notícias, 3 de fevereiro de 1940.

${ }^{102}$ Estado da Bahia, 23 de fevereiro de 1955; Estado da Bahia, 27 de fevereiro de 1952.

${ }^{103}$ Leal, Pergunte ao seu avô, pp. 205-09; Goés, 50 anos, pp. 40-51.
} 
do trio elétrico, "oficial", organizado pela prefeitura, sancionando e talvez esperando cooptar, em parte, a popularidade do fenômeno. ${ }^{104}$ Os trios elétricos colocaram problemas para a popularidade das batucadas e até mesmo para a centralidade do samba no carnaval baiano. Os trios inicialmente tocavam frevo, que era popular no carnaval do Recife. No entanto, o aumento da popularidade, nas décadas de 1930 e 1940, das associações de batucada de carnaval dos bairros pobres e da classe trabalhadora facilitou a celebração, realizada principalmente por jornalistas, da batucada afro-baiana no carnaval. O carnaval, é claro, foi sem dúvida a mais importante festa popular de Salvador para a configuração da identidade regional baiana. Como Natalie Zemon Davis argumentou, há muito tempo, apesar de dramáticas mudanças na ordem social serem raras, o poder da prática do carnaval é que ao longo do tempo ele estende os limites do aceitável. O que é inicialmente uma inversão, ou talvez apenas uma exceção, torna-se cada vez mais normativo. ${ }^{105} \mathrm{~A}$ dinâmica da "Era das batucadas" contribuiu para a consolidação das práticas musicais afro-baianas: a batucada e o samba, como elementos vitais do que significava a Bahia e do que "baiano" passou a significar durante a Era Vargas. As batucadas desempenharam papéis importantes na reformulação da baianidade entre 1930 e 1950, uma vez que práticas culturais afro-baianas e os próprios afro-baianos foram celebrados como "a poderosa força propulsora que movia o carnaval baiano". ${ }^{106}$ Mesmo depois de 1950 as batucadas não desapareceram completamente. Elas e uma série de afoxés continuaram a ser uma ponte de identificação étnica e de protagonismo cultural entre os clubes afrocêntricos do fim do século XIX e início do século XX, por um lado, e os afoxés e blocos afros do fim do século XX e início do XXI.

Texto apresentado em 10 de maio de 2012 e aceito em 23 de junho de 2012

\footnotetext{
${ }^{104}$ Fratelli Vita, um fabricante de refrigerante com uma longa história de patrocínio do carnaval, assumiu o patrocínio do trio, que vinha aparecendo nos gritos de carnaval em 1953 e 1954: Diário de Notícias, 4 de fevereiro de 1954. A Tarde, 7 de fevereiro de 1955.

${ }^{105}$ Natalie Zemon Davis, Society and Culture in Early Modern France: Eight Essays, Stanford: Stanford University Press, 1975, capítulos 4 e 5.

${ }^{106}$ Cláudio Tavares e Pierre Verger, "Afoxé, ritmo bárbaro da Bahia”, O Cruzeiro, v. 20, n. 32 (29 de maio de 1948), p. 57.
} 


\title{
Resumo.
}

Depois de 1930, os três clubes de elite do carnaval baiano sofriam economicamente e se retiravam do carnaval. As batucadas emergiram e em parte preencheram o vácuo, ritualizando a presença da cultura e sociabilidade da classe trabalhadora afro-mestiça no carnaval. Neste período, os políticos e, especialmente, jornalistas comemoravam a batucada e o samba como centrais para o carnaval, contribuindo para a consolidação das práticas musicais afro-mestiças como elementos vitais do que a Bahia significava e do que "baiano" passou a significar durante a era Vargas. Embora, após 1950, o trio elétrico e o ressurgimento dos clubes de elite tenham encerrado a "Era das Batucadas," elas desempenharam papéis importantes na reformulação da baianidade, entre 1930 e 1950, e forneceram uma ponte de identificação étnica e cultural entre os afoxés e clubes afros do século XIX e início do século XX, por um lado, e os afoxés e blocos afros do final do século XX e início do XXI.

Palavras chave: Bahia - carnaval - batucadas - samba - Era Vargas

\begin{abstract}
After 1930, as Bahia's three elite carnival clubs suffered economically and withdrew from carnival, the emerging batucadas partly filled the vacuum and ritualized the presence of working-class African-Bahian culture and sociability within Carnival. At this point, politicians and especially journalists celebrated both the batucada and samba as central to Carnival, contributing to the consolidation of African-Bahian musical practices as vital elements of what Bahia meant and what "Bahian" had come to mean during the Vargas era. Although the trio elétrico and the revival of the elite clubs after 1950 ended the "Era of the Batucadas," the batucadas had played important roles within the reformulation of baianidade between 1930 and 1950 and provided a bridge of ethnic identification and cultural agency between the afro-centric clubs of the late nineteenth and early twentieth century on the one hand, and the afoxés and blocos afros of the late twentieth and twenty first century.
\end{abstract}

Keywords - Bahia - carnival - batucadas - samba - Vargas era 